\title{
A Hydrothermal-Sedimentary Context for the Origin of Life
}

\author{
F. Westall, ${ }^{1}$ K. Hickman-Lewis, ${ }^{1,2}$ N. Hinman, ${ }^{3}$ P. Gautret, ${ }^{4}$ K.A. Campbell, J.G. Bréhéret, \\ F. Foucher, ${ }^{1}$ A. Hubert, S. Sorieul, A.V. Dass, ${ }^{1}$ T.P. Kee, ${ }^{8}$ T. Georgelin, ${ }^{1,9}$ and A. Brack ${ }^{1}$
}

\begin{abstract}
Critical to the origin of life are the ingredients of life, of course, but also the physical and chemical conditions in which prebiotic chemical reactions can take place. These factors place constraints on the types of Hadean environment in which life could have emerged. Many locations, ranging from hydrothermal vents and pumice rafts, through volcanic-hosted splash pools to continental springs and rivers, have been proposed for the emergence of life on Earth, each with respective advantages and certain disadvantages. However, there is another, hitherto unrecognized environment that, on the Hadean Earth $(4.5-4.0 \mathrm{Ga})$, would have been more important than any other in terms of spatial and temporal scale: the sedimentary layer between oceanic crust and seawater. Using as an example sediments from the 3.5-3.33 Ga Barberton Greenstone Belt, South Africa, analogous at least on a local scale to those of the Hadean eon, we document constant permeation of the porous, carbonaceous, and reactive sedimentary layer by hydrothermal fluids emanating from the crust. This partially UV-protected, subaqueous sedimentary environment, characterized by physical and chemical gradients, represented a widespread system of miniature chemical reactors in which the production and complexification of prebiotic molecules could have led to the origin of life. Key Words: Origin of life-Hadean environmentMineral surface reactions-Hydrothermal fluids-Archean volcanic sediments. Astrobiology 18, 259-293.
\end{abstract}

\section{Introduction}

I $\mathrm{N}$ THIS SECTION, we briefly overview the basic requirements for prebiotic chemistry and the emergence of life, underlining the importance of the mineral world, in particular for the former. Considering the significance of the geological environment for the origin of life, we outline the present understanding regarding environmental conditions reigning on early Earth. We then consider various previously proposed environments in which life might have arisen. With this background, the objective of our study is to show, using an examination of Paleoarchean volcanic sediments strongly influenced by hydrothermal fluids as a benchmark, that volcanic sediments could have played an important role in prebiotic chemistry and in the increasing complexity of prebiotic chemical systems eventually leading to the origin of life.

\subsection{Requirements for prebiotic chemistry and the emergence of life}

When considering the local environment (or environments) in which life could have emerged, the prebiotic processes that led to the origin of cellular life and the physical and chemical conditions in which these processes could occur need to be taken into account. There are three critical steps that lead toward cell formation (Table 1): (1) concentration of the molecular components that participate

\footnotetext{
${ }^{1}$ CNRS-Centre de Biophysique Moléculaire, Orléans, France.

${ }^{2}$ Dipartmento di Scienze biologiche, geologiche e ambientale, Università di Bologna, Bologna, Italy.

${ }^{3}$ Geosciences, University of Montana, Missoula, Montana, USA.

${ }^{4}$ University of Orléans, ISTO, UMR 7327, Orléans, France, and CNRS, ISTO, UMR 7327, Orléans, France, and BRGM, ISTO, UMR 7327, Orléans, France.

${ }^{5}$ School of Environment, The University of Auckland, Auckland, New Zealand.

${ }^{6}$ GéoHydrosytèmes Continentaux, Faculté des Sciences et Techniques, Université François-Rabelais de Tours, Tours, France.

${ }^{7}$ University of Bordeaux, CNRS, IN2P3, CENBG, UMR5797, Gradignan, France.

${ }^{8}$ School of Chemistry, University of Leeds, Leeds, UK.

${ }^{9}$ Sorbonne Universités, UPMC Paris 06, CNRS UMR 7197, Laboratoire de Réactivité de Surface, Paris, France.

(C) Frances Westall et al., 2018; Published by Mary Ann Liebert, Inc. This Open Access article is distributed under the terms of the Creative Commons License (http://creativecommons.org/licenses/by/4.0), which permits unrestricted use, distribution, and reproduction in any medium, provided the original work is properly credited.
} 
Table 1. Important Processes for the Emergence of Life

\begin{tabular}{lcc}
\hline Process & \multicolumn{1}{c}{ Rationale } & Means \\
\hline $\begin{array}{c}\text { Concentration } \\
\text { of prebiotic } \\
\text { components }\end{array}$ & $\begin{array}{c}\text { Favors probability of interactions between } \\
\text { molecules }\end{array}$ & $\begin{array}{c}\text { Confinement within small compartments } \\
\text { (pores), voids and interstitial spaces on } \\
\text { mineral surfaces, chelation to mineral } \\
\text { surfaces, including silica gel, etc. }\end{array}$ \\
$\begin{array}{c}\text { Conformation, } \\
\text { structuration, } \\
\text { and stabilization }\end{array}$ & $\begin{array}{c}\text { Molecular orientation affects reactions } \\
\text { between molecules }(e . g ., \text { stereochemistry); } \\
\text { prevention of molecular degradation }(e . g ., \\
\text { of ribose); permits reactivity } \\
\text { Complexification }\end{array}$ & $\begin{array}{c}\text { Buildup and polymerization of } \\
\text { macromolecules necessary for prebiotic } \\
\text { processes and emergence of life }\end{array}$ \\
\hline
\end{tabular}

in prebiotic reactions and control of water activity, (2) stabilization and structural conformation of molecules, and (3) chemical evolution through complexification. Experimental data show that the aforementioned processes are greatly aided by the presence of mineral surfaces, as summarized by Hazen and Sverjensky (2010) and Dass et al. (2016), thus underlining the importance of the mineral world for prebiotic chemistry and the emergence of life.

(1) Concentration: Concentration of essential biomolecules is of prime importance in understanding the origins of life. The effectiveness of interfaces between minerals and aqueous solutions in this regard was highlighted by Hazen and Sverjensky (2010). Several studies (Hazen, 2001, 2004; Cleaves et al., 2012; Grosch and Hazen, 2015) have emphasized the importance of crystal surfaces and how they provide an effective substrate upon which the concentration and catalysis of prebiotic molecules could be possible. Adsorption is of critical importance in assisting concentration. Concentration and "crowding" of molecules is essential in order to promote reactions between the molecules that could lead to coevolution of their reaction mechanisms (Copley et al., 2007). Spitzer and Poolman (2009) underlined the importance of "micro-spaces" for confinement "that select[s] (create, import, retain, or expel) protobiomolecules." Various types of microspaces have been suggested, such as iron sulfide compartments in hydrothermal vents (Russell and Hall, 1997), porous "beehive-like" hydrothermal structures (such as those described by Tivey and Delaney, 1986), pores at the surfaces of minerals (Hazen and Sverjensky, 2010), crevices within minerals (e.g., pumice; Brasier et al., 2011, 2013), among others. Certain mineral surfaces and/or intracrystalline spaces can also concentrate organic molecules, such as clays (Reid and Orgel, 1967), zeolites (Smith et al., 1999), and feldspars (Parsons et al., 1998). Spitzer and Poolman (2009) suggested pore sizes of $0.1-1.0 \mu \mathrm{m}$ as being of relevant size for molecular concentration. In addition, the recognition that contemporary biological cells retain, concentrate, and manipulate biomolecules within an environment that is inherently a hydrogel (Pollack, 2001; Trevors and Pollack, 2005; Trevors, 2010, 2011a, 2011b; Saha et al., 2014) has led to suggestions that geologically relevant gel environments in which molecular crowding could take place would also represent an environment of prebiotic microspace.

(2) Stabilization and structural conformation: Molecular stabilization plays an important role in prebiotic chemistry.
Given the short lifetimes of biomolecules, such as ribose, it is hard to envisage the reactivity of such fragile molecules in the harsh conditions at the surface of early Earth. Minerals could potentially favor molecular stabilization, prolong their lifetimes, and thus prevent their rapid degradation, for example, the stabilization of ribose on minerals (Georgelin et al., 2013, Akouche et al., 2016, and Lambert et al., 2010, on silicates, or Ricardo et al., 2004, on borates). Structural conformation and orientation of molecules permits reactivity and selectivity of organic reactions. Brack and Orgel (1975) showed that the addition of salts, for instance $0.1 \mathrm{M}$ $\mathrm{NaCl}$, spontaneously produces an asymmetrical beta-sheet bilayer of peptides (with a hydrophobic interior and a hydrophilic exterior) (note, for comparison, that the concentration of $\mathrm{NaCl}$ in modern seawater is $0.6 \mathrm{M}$ ). Bertrand and Brack (2000) demonstrated catalysis of beta-sheet formation on cadmium sulfide. Jonsson et al. (2009) experimentally showed that L-glutamate could be adsorbed onto the surface of rutile in salt solutions and that the role of orientation in adsorption could potentially affect chemical reactivity.

(3) Chemical evolution: Studies in systems chemistry at the molecular level support indications of the progressive buildup of molecular complexity (Ruiz-Mirazo et al., 2014; Islam and Powner, 2017). Dass et al. (2016) emphasized the relevance of minerals in stochastic systems chemistry. Patel et al. (2015), using a systems chemistry approach, suggested that the precursors of ribonucleotides, amino acids, and lipids originated simultaneously from a single source. Clearly, we still do not understand the fundamental mechanisms by which the first forms of biological life emerged. However, it is recognized that such emergence resulted from energy being transduced from one form to another and for some of that energy to have been used to drive spontaneous selforganization, or complexity. In this context, "complexity" refers to the mutual and integrated communication between chemical species rather than the variety of chemical species present per se. It is only through this connectivity that self-organization is revealed. While we recognize the fundamental importance of this concept to the emergence of life, a detailed discussion of biosynthesis is beyond the scope of this paper. The interested reader is encouraged to read excellent contributions on this subject by, for example, Martin and Russell (2003) and Russell et al. (2010). 
The above, briefly described processes that led to the emergence of life were controlled by physicochemical conditions of the environment, including element availability, water temperature, $\mathrm{pH}$, ionic strength, energy, irradiation, gradients, and molecular diffusion (Table 2). C, H, $\mathrm{N}, \mathrm{O}$, and $\mathrm{P}$ are the basic ingredients for prebiotic chemistry, as elements with minor endogenic and major exogenic origins (Pizzarello and Shock, 2010; Dass et al., 2016). Other elements, such as $\mathrm{S}$ and transition metals, become important for the emergence of cellular life and primitive metabolisms. Temperature, in addition to concentration and pressure, controls the kinetics of the many reactions that occur in prebiotic chemistry: it facilitates the increased probability of intermolecular collision and helps overcome energy barriers. Higher temperatures also result in dehydration leading to the condensation (concentration) of molecules, mainly on mineral surfaces. However, temperature is limiting to cellular life. Above $\sim 120^{\circ} \mathrm{C}$, molecular bonds break, such as RNA/ DNA nucleotides (Kashefi and Lovley, 2003). Molecular reactions in aqueous solution are linked to the $\mathrm{pH}$ of the solution, with different $\mathrm{pH}$ values favoring different kinds of reactions, thus permitting the emergence of a wide range of organic molecules (e.g., Gull et al., 2015). Reactions requiring sugars, for instance, require an alkaline $\mathrm{pH}$, while many others can take place at acidic $\mathrm{pH}$ values. Ionic strength is an important factor for two reasons. In solution, the nature and the activity of salts can stabilize and affect structural orientation of organic species and polymers, leading to spontaneous molecular assembly, for example, the formation of surfactant micelles (Spitzer and Poolman, 2009). It also influences the adsorption of organic molecules onto mineral surfaces; for example, an increase of ionic strength overcomes electrostatic interactions, thus controlling adsorption. This contributes to the selection of organic molecules that participate in the emergence of cellular life (Spitzer and Poolman, 2009). Ionic strength can be controlled by the nature of mineral and chemical functions available at the surface of the mineral.

All reactions require energy. Ionizing radiation is an important source of energy for prebiotic chemistry. Its ubiquity, energy introduction method, and the effectiveness of its reactions via free radicals make it very efficient for prebiotic chemistry, both in frozen ices (for extraterrestrial processes) and in water (for processes occurring on early Earth) (Negrón-Mendoza et al., 2016). For example, cosmic radiation at various wavelengths has been invoked as an extraterrestrial cause of enantiomeric excesses of organic molecules in carbonaceous chondrites (Bonner, 1991; Bailey, 2001). Meinert et al. (2016) reported obtaining ribose and other sugars from UV irradiation of interstellar ice analogues. Other potential sources of radiation could have come from ${ }^{40} \mathrm{~K}$, which would have been relatively enriched in Hadean granitoids. However, this would require weathering and exposure on the relatively rare Hadean landmasses. Other sources of energy include exothermic reactions or heat from hydrothermal systems. Energy for primitive cellular metabolisms (chemotrophic) was provided by the oxidation of reduced inorganic compounds (e.g., $\mathrm{NH}_{4}, \mathrm{NO}_{2}, \mathrm{SO}_{3}, \mathrm{SO}, \mathrm{H}_{2}$, and $\mathrm{Fe}^{(\mathrm{II})}$ ), as well as the oxidation of organic compounds, reactions that all produce the phosphorylated, energy storage molecule adenosine triphosphate (ATP).
The radiation environment can have both positive and negative consequences. While radiation serves as an energy source for certain prebiotic reactions, it is generally deleterious to both molecular complexification and cellular life, inducing molecular breakdown. Note, however, that certain present-day extremophilic microorganisms are able to survive high doses of radiation (Deinococcus radiodurans survives up to 5000 Gy of radiation; Cox and Battista, 2005) and that early life was clearly able to withstand the relatively high radiation environment of early Earth (Westall et al., 2006a).

Gradients (e.g., of temperature, $\mathrm{pH}$, ionic strength, energy) are a means of maintaining systems out of equilibrium. They aid dissipation of energy, and sinks of dissipated energy are potential reaction sites (Dass et al., 2016). Gradients are also important for the functioning of protocells, again mainly for energy dissipation. Of prime importance is also the diffusion of essential components for prebiotic chemistry and primitive metabolisms, transported in hydrothermal fluids, seawater, pore waters (in porous materials), and mixtures of these into and out of compartments (gels, vesicles, pores in rocks and minerals) in which prebiotic chemistry could take place.

\subsection{Early Earth environment}

As the context for prebiotic chemistry and the emergence of life, in this section we review what is known or surmised of the environment of early Earth (see also reviews by Russell and Arndt, 2005, and Kamber, 2015). For this we need to keep in mind that, given the lack of preserved Hadean (4.5-3.85 Ga, sensu Bleeker, 2004; Kamber 2015) crust, our understanding of the Hadean environment is extremely sketchy. Moreover, there will be a difference between the global-scale situation and the microscopic- to local-scale environments in which prebiotic chemistry occurred and protocells emerged. The lack of Hadean crust has been attributed to destruction and resurfacing during the period of the hypothesized Late Heavy Bombardment, 4.1$3.85 \mathrm{Ga}$ (Bottke et al., 2012), when the inner planets were subjected to intense and deleterious bombardment by extraterrestrial bodies (Kemp et al., 2010; Marchi et al., 2014), and to catastrophic recycling of the early crust, possibly combining collapse of the single lithospheric plate that covered the planet (stagnant lid, after Griffin et al., 2014) with episodic, short-lived plate tectonics (Debaille et al., 2013). However, the Late Heavy Bombardment model has since been revisited to imply that the impact "spike" resembled not catastrophic bombardment but rather a longdrawn-out period of more intense bombardment throughout the Hadean (Zellner, 2017). Note that, in a recent reevaluation of the models pertaining to asteroid bombardment during the Hadean, Sleep (2016) estimated that the impacts would have been relatively benign and there would not have been more than one impact severe enough to affect early life-forms.

Despite the lack of crustal preservation, some information about the Hadean can be deduced from modeling (e.g., Johnson et al., 2014), from proxies such as the characteristics of zircon crystals eroded from buried Hadean crust and recycled into younger sedimentary formations (e.g., Mojzsis et al., 2001; Wilde et al., 2001; Nemchin et al., 2006), and 


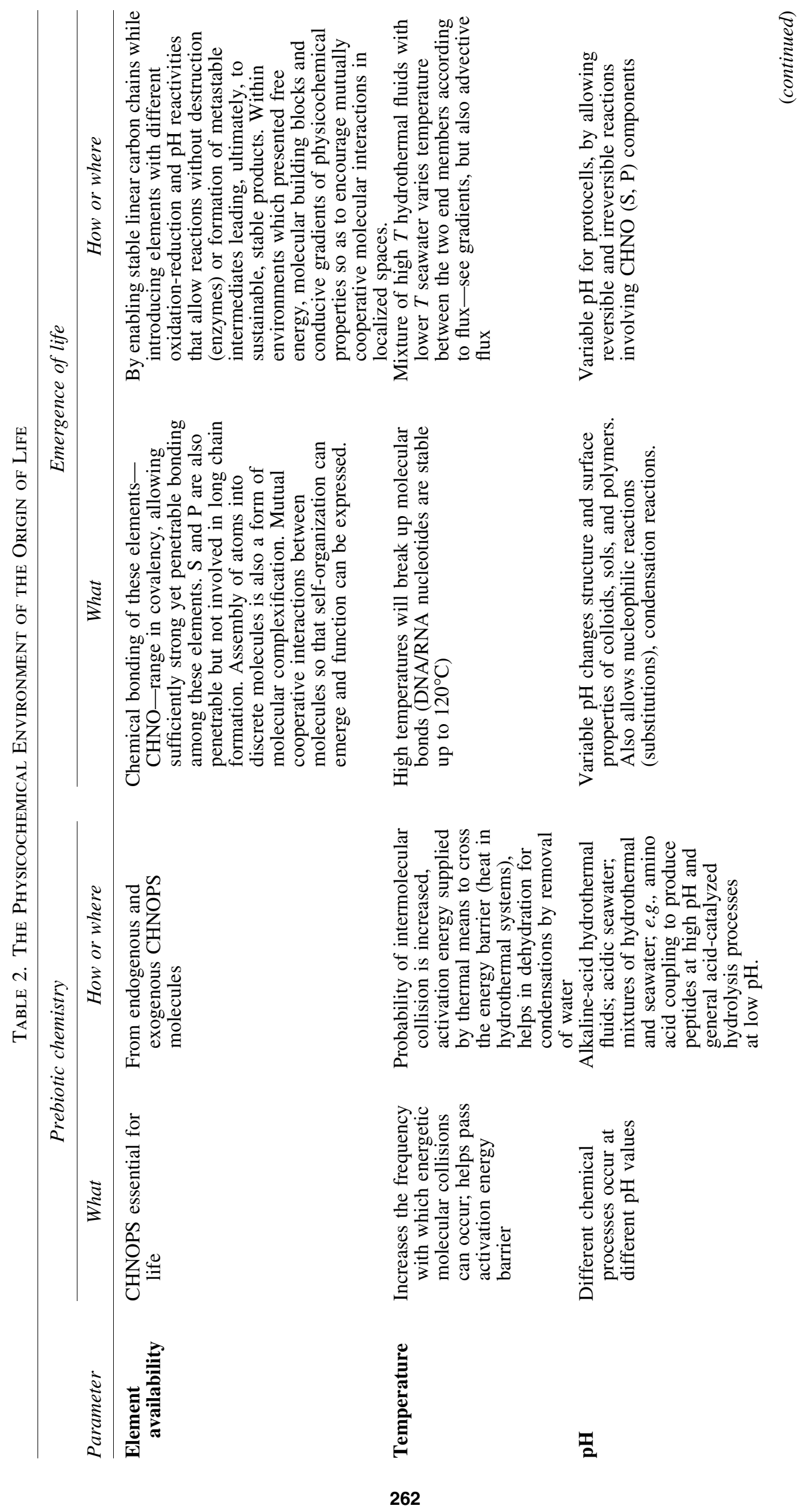




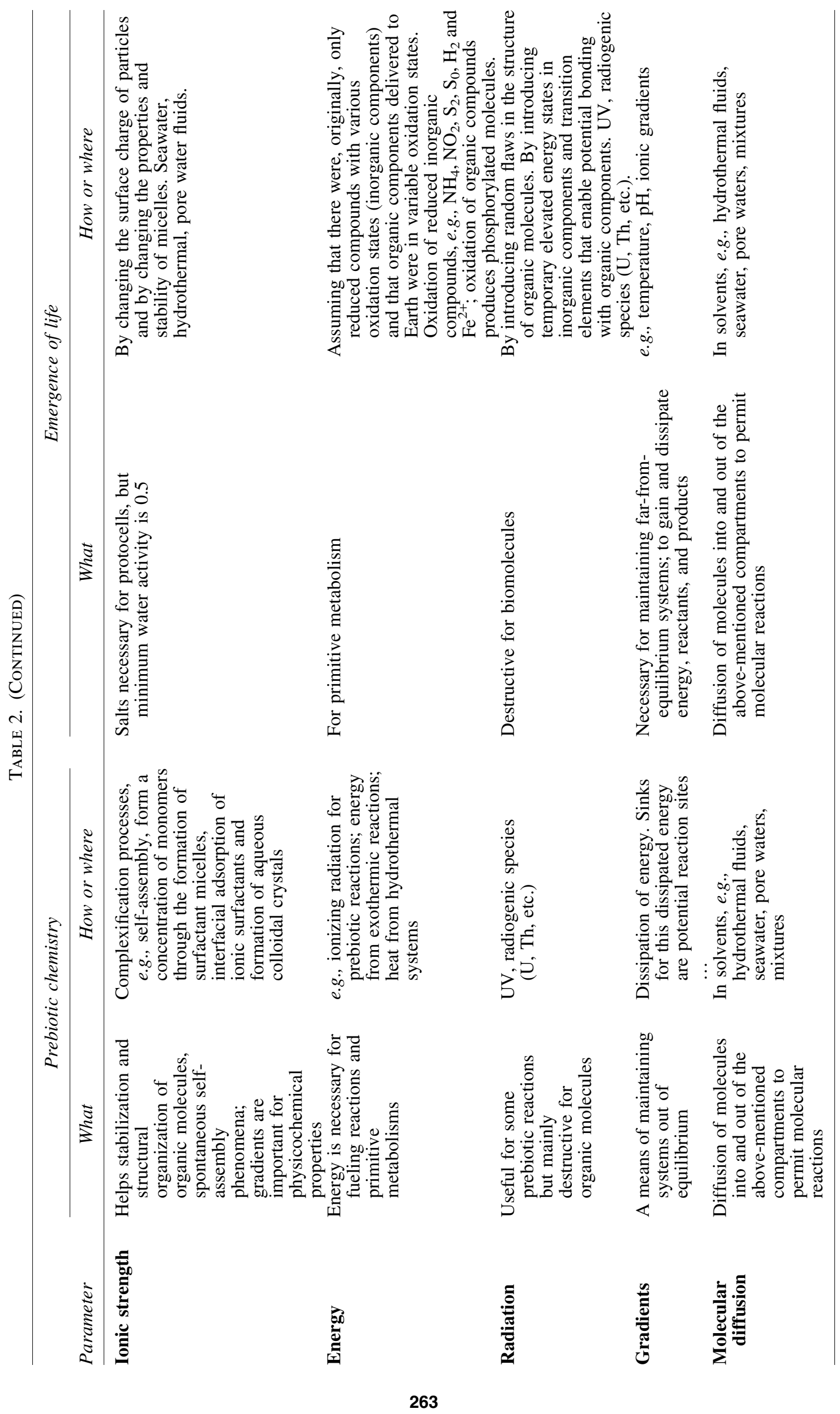


from remnant geochemical signatures in the preserved Eoarchean-Paleoarchean cratons (e.g., Kamber et al., 2003). (Note that carbon with a $\delta^{13} \mathrm{C}$ signature of $-24 \%$ was detected in inclusions in one Hadean zircon crystal [Bell et al., 2015], a value that could be either biogenic or abiogenic.)

The kind of global-scale information relevant to prebiotic chemistry concerns the composition of the crust (i.e., mineral availability); the presence of water, the distribution of emergent land masses; temperatures; indications of additional physicochemical characteristics of the water (temperature, $\mathrm{pH}$, ionic strength); and additional parameters such as gradients, diffusion, and energy sources for prebiotic reactions and cellular metabolism.

From geochemical analyses of Eoarchean (3.85-3.5 Ga) cratons underlain by Hadean crust, it appears that the Hadean crust had a mafic signature (Kamber et al., 2003). Thus, typical minerals available would have included the ferromagnesian minerals olivine and pyroxene, as well as plagioclase and calcic feldspars and the iron oxide, magnetite. The products of aqueous and hydrothermal alteration of these minerals would have been varied, including phyllosilicates (montmorillonite, smectites, and zeolites) and $\mathrm{Fe}$ and $\mathrm{Ti}$ oxides. Associated hydrothermal minerals could have included mainly $\mathrm{Fe}$ (with more minor $\mathrm{Ca}$ and $\mathrm{Mg}$ ) carbonates, zeolites, ferrous and ferric oxyhydroxides, various sulfides (e.g., Fe, $\mathrm{Ni}, \mathrm{Zn}$ ), and amorphous silica (gels, cherts).

Evidence for water on the Hadean Earth comes from mineralogical and geochemical sources. Zircon crystals, formed during remelting of buried, hydrated Hadean crust, were eroded from subsequently exposed crust and were deposited as inherited detrital particles in younger, Mesoarchean (3.1-2.85 Ga) sediments (e.g., Mojzsis et al., 2001; Wilde et al., 2001). The existence of detrital Hadean zircons suggests that liquid water was present at the surface of the Hadean Earth, possibly already by $4.36 \mathrm{Ga}$, the age of the oldest zircons (Mojzsis et al., 2001; Wilde et al., 2001; Nemchin et al., 2006). Kramers (2003) similarly concluded that there was water on the Hadean Earth, based on a comparison of the abundances of light and gaseous elements $(\mathrm{H}, \mathrm{C}, \mathrm{N}, \mathrm{Ne}, \mathrm{Ar}, \mathrm{Cl}, \mathrm{Br}, \mathrm{Kr}, \mathrm{I}$, and $\mathrm{Xe})$ in the outer Earth reservoirs (atmosphere-hydrosphere, continental crust, and MORB-source mantle) with solar matter and carbonaceous chondrites. The temperature of water in the Hadean crust has been debated. An initial estimate of $<150^{\circ} \mathrm{C}$ based on heavy $\delta^{18} \mathrm{O}$ isotopes by Wilde et al. (2001) in Hadean zircon crystals was demonstrated to be erroneous and, as indicated by Nemchin et al. (2006), due to later resetting or contamination. Hadean crustal temperatures would have governed hydrothermal circulation and the temperatures of hydrothermal fluids. Sleep (2000) and Zahnle et al. (2007) modeled relatively high heat flow rates in the early crust of from 160 up to $500 \mathrm{~mW} / \mathrm{m}^{2}$, due to heating by the decay of radiogenic isotopes, such as $\mathrm{U}, \mathrm{Th}, \mathrm{Al}$, and $\mathrm{K}$. More recently, studies on inclusions in Hadean zircons suggest that they formed at relatively low temperatures and, therefore, heat flow in the Hadean crust was low, $\sim 40-80 \mathrm{~mW} / \mathrm{m}^{2}$ (Hopkins et al., 2010), that is, values as low as the lowest heat flow measured on the present-day Earth. For a recent review of the heat flow constraints and interactions of the hydrosphere/lithosphere with respect to the inset of plate tectonics, the interested reader is referred to the work of Korenaga (2013), who suggested that, on the basis of the- oretical considerations and available observational constraints, plate tectonics driven by mantle heat flow could have initiated in the Hadean.

Bickle et al. (1994) concluded from thermal, tectonic, and isostatic constraints that, at least during the Archean (3.85 to $\sim 2.5 \mathrm{Ga}$ ), oceanic basins contained several kilometers of water but that the Archean continents were mostly submerged and characterized by shallow-water sediment sequences. The thin layers of sediments preserved from the Eoarchean indicate that, during that period, there was little exposed landmass. This seems also to have been the situation for the Hadean (Russell and Arndt, 2005).

Temperatures at the early Earth surface are highly debated, especially considering lower illumination from the "Faint Young Sun" (Sagan and Mullen, 1972). Various processes have been evoked to explain conditions conducive to the presence of liquid water on the Hadean/Archean Earth. For instance, Walker (1985) and Kasting (1993) modeled a thicker $\mathrm{CO}_{2}$ atmosphere. This is supported by mineralogical data, for example, the presence of siderite in equilibrium with magnetite in Archean shallow-marine sediments (Rosing et al., 2010). It has been hypothesized that the early atmosphere contained certain amounts of "greenhouse" gases, such as methane (Pavlov et al., 2000), or volcanically outgassed nitrogen (Mather et al., 2004; Goldblatt et al., 2006). However, at least with respect to $\mathrm{CH}_{4}$, a large amount of such gases in the atmosphere would have led to an organic haze, which would have prevented the penetration of sunlight to the surface and resulted in the freezing of Earth (Haqq-Misra et al., 2008). Yet another hypothesis evokes a lower albedo than today for early Earth on the grounds that cloud nuclei today consist largely of oxidized sulfur species of biological (plant and algal, i.e., eukaryotic) origin and the lack of such evolved organisms in the Hadean and the Archean would have hindered cloud formation (Rondanelli and Lindzen, 2010; Rosing et al., 2010). Note that Sleep et al. (2008) proposed that the initial solar greenhouse might have been hot based on calculations related to tidal and internal heat flux.

Wide-ranging estimates of Paleoarchean (3.5-3.1 Ga) ocean temperatures made by using oxygen, silicon, and hydrogen isotopic signatures preserved in chert sediments dating back to $3.5 \mathrm{Ga}$ concur that seawater was above freezing, at least at the sediment-seawater layer. Cooler temperatures down to $\sim 26^{\circ} \mathrm{C}$ were interpreted by Hren et al. (2009) and Blake et al. (2010), while warmer seawater temperatures $\left(>50-60^{\circ} \mathrm{C}\right)$ have been estimated from the isotopic studies of van den Boorn et al. (2010), MarinCarbonne et al. (2014), and Tartèse et al. (2017). The studies estimating higher temperatures note the influence of hydrothermal fluids on ambient seafloor temperatures.

Apart from the isotopic record, mineralogical and sedimentological data from the Paleoarchean also provide constraints on surface temperatures. The sediments in the Onverwacht Group of the Barberton Greenstone Belt document typical marine sedimentary deposition (Tice and Lowe, 2004; de Vries et al., 2010; Westall et al., 2015a). Some of the shallow-water sediments record tidal signatures in the form of oscillatory ripple marks (Westall et al., 2015a), evaporite minerals (Lowe and Fisher Worrell, 1999), and desiccation cracks associated with evaporitic mineral suites (Westall et al., 2006a), all indicating formation in a relatively 
warm environment, since the coastal regions would be the first to freeze. Further geological evidence comes from mineralogy with relatively high concentrations of atmospheric $\mathrm{CO}_{2}$, which supports temperatures warm enough to permit liquid water, as interpreted on the basis of the presence of siderite (Hessler et al., 2004) and nahcolite (Tice and Lowe, 2006) in the Paleoarchean sediments. On one hand, it was recently suggested that the Paleoarchean Earth was glaciated, based on finely laminated sediments in the Paleoarchean Barberton Greenstone Belt that were interpreted to be glacial diamictites (de Wit and Furnes, 2016). However, the sediments described by de Wit and Furnes (2016) are very similar to other finely laminated sediments from the Onverwacht Group that exhibit clear indications of deposition in shallow, quiet water environments in at least warm seawater.

But what of temperatures during the Hadean? As noted above, the indication of hydrated, Hadean mafic crust (zircon formation) and light element abundances suggest that there was indeed water at the surface of the crust. However, Sleep et al. (2008) concluded that the critical surface temperatures permitting liquid water in a Hadean $\mathrm{CO}_{2}$ atmosphere could have been maintained for only up to 20 million years following the cooling of Earth after the Moon-forming impact. Their estimations, however, do not take into account the aforementioned greenhouse gases, such as methane (Pavlov et al., 2000) or volcanically emitted nitrogen (Mather et al., 2004; Goldblatt et al., 2006). Zahnle et al. (2007) noted that removal of $\mathrm{CO}_{2}$ from the early atmosphere by subduction of precipitated carbonate could lead to a cold, frozen surface; but, if carbonate removal (subduction) were inefficient, $\mathrm{CO}_{2}$ partial pressures in the atmosphere would be sufficient to keep the surface warm enough to maintain liquid water. Indeed, the rheology of Hadean crust differed from that of later crust and may have been unable to support efficient modern-style plate tectonics (Stern, 2005, 2008). In fact, the earliest preserved evidence of modern tectonic cycling is at 3.2 Ga (Heubeck and Lowe, 1994; Stern, 2005; Van Kranendonk et al., 2010). Removal of atmospheric $\mathrm{CO}_{2}$ by alteration of atmospheric dust caused by impacts was also invoked by Nisbet and Sleep (2001). Russell and Arndt (2005) suggested that atmospheric temperatures during the Hadean possibly oscillated between warm to hot and shortlived cold to freezing periods, with continuous eruption of volcanic $\mathrm{CO}_{2}$ into the atmosphere rapidly heating it up (i.e., hysteresis).

It is clear that, owing to lack of geological evidence, the jury is out on the question of whether the surface of the Hadean Earth was frozen. Nevertheless, noting the discussion above about the geological evidence for liquid and warm to hot seawater temperatures (up to $\sim 60^{\circ} \mathrm{C}$ ) by $3.5 \mathrm{Ga}$, the presence of more abundant radiogenic heat sources in the crust ( $\mathrm{U}, \mathrm{Th}$, and $\mathrm{K}$ ), and the fact that the crust was likely characterized by abundant hydrothermal activity ( $c f$. Russell and Arndt, 2005), for the purposes of this study we assume that, during the Hadean, seawater at the interface with the crust must have been liquid, irrespective of whether deeper bodies of water were covered with ice at their surfaces.

The $\mathrm{pH}$ of the early oceans has also been a source of debate. The high partial pressure of $\mathrm{CO}_{2}$ in the HadeanPaleoarchean atmosphere would have produced acid rain and concomitantly acidic seawater (Grotzinger and Kasting,
1993). This is supported through modeling by Morse and Mackenzie (1998), who estimated a $\mathrm{pH} \sim 5.8$ in the Hadean, gradually increasing to more neutral values in the Archean. On the other hand, Kempe and Degens (1985) proposed that the Hadean oceans were alkaline, owing to seawater alteration of the largely mafic/ultramafic ocean crust, which would have led to the deposition of significant amounts of carbonate. Circumneutral to alkaline $\mathrm{pH}$ values for the early oceans, similar to those of modern oceans, were also suggested by Friend et al. (2008) on the basis of trace elemental analyses of surviving Eoarchean rocks from the Isua Greenstone Belt in Greenland. Against this latter suggestion and in favor of acidic $\mathrm{pH}$, the rock record from Early Archean sedimentary formations does not document large-scale carbonate deposits, although small amounts of carbonates did form from alteration of the mafic/ultramafic volcanics. Moreover, ironcontaining formations are prevalent in the Paleoarchean rock formations, but $\mathrm{Fe}$ formation in open water cannot occur at $\mathrm{pH}$ 8 in a massive $\mathrm{CO}_{2}$ atmosphere, thus arguing for generally acidic conditions.

\subsection{Environments in which life could have emerged}

The requirements for prebiotic processes and very early cellular life (Tables 1 and 2), together with what may be surmised about Hadean surface environments, must be taken into account when considering a geological scenario for the emergence of life. We have subdivided proposed environments from previous literature as follows: (1) submarine hydrothermal vents, (2) floating pumice rafts, (3) subaerial geysers, and (4) volcanic-hosted splash pools. Their properties with respect to prebiotic processes and the emergence of life are summarized in Tables $3 a-3 d$. Here, we briefly discuss each kind of environment and assess the advantages and shortcomings in their suitability as locations for life's emergence.

1.3.1. Submarine hydrothermal vents. Submarine hydrothermal vents were first proposed as a possible location for the origin and early evolution of life by Baross and Hoffman (1985) on the grounds that physical and chemical gradients in hydrothermal systems "provided the necessary multiple pathways for the abiotic synthesis of chemical compounds, origin and evolution of 'precells' and 'precell' communities, and ultimately the evolution of free-living organisms." Their hypothesis was further developed by Russell and Hall (1997), who proposed that the emergence of life within iron monosulfide bubbles (the mineral habit of which could produce "membranes" that mimic cell boundaries) formed at the gradient between hot (e.g., up to $150^{\circ} \mathrm{C}$ ) alkaline hydrothermal fluids and lower-temperature (but still hot, $\sim 90^{\circ} \mathrm{C}$ ) acid seawater. The membranes would have catalyzed the synthesis of organic anions by hydrogenation and carboxylation of hydrothermal organic primers, resulting in the condensation of the organic molecules to polymers. Martin and Russell (2003) and Martin et al. (2008) furthered this scenario from the perspective of primitive metabolisms, drawing attention to the similarity between the $\mathrm{H}_{2}$-dependent chemistry of transition-metal sulfide catalysts and those catalysts and metabolisms involved in the $\mathrm{CO}_{2}$ reducing biochemistry of modern microorganisms. The exothermic synthesis of acetate and $\mathrm{CH}_{4}$ from $\mathrm{H}_{2}$ and $\mathrm{CO}_{2}$ 


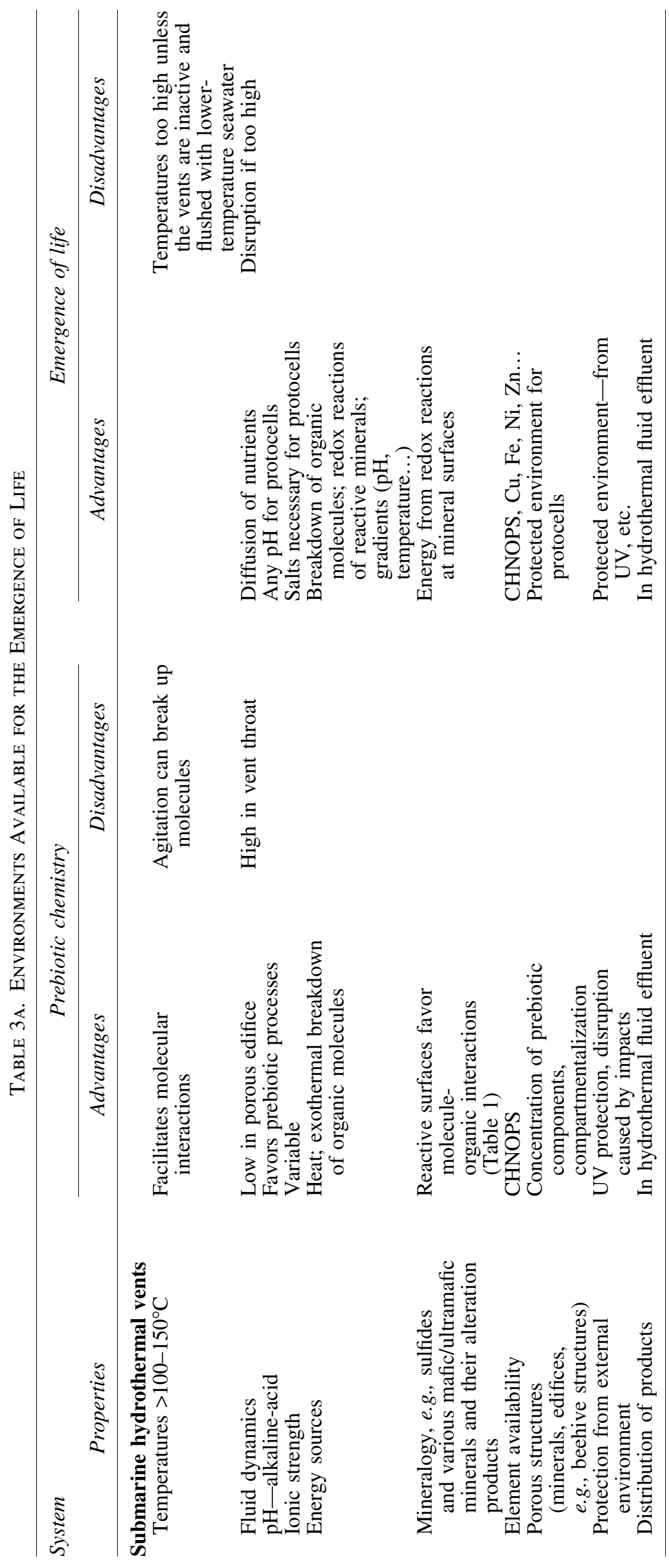




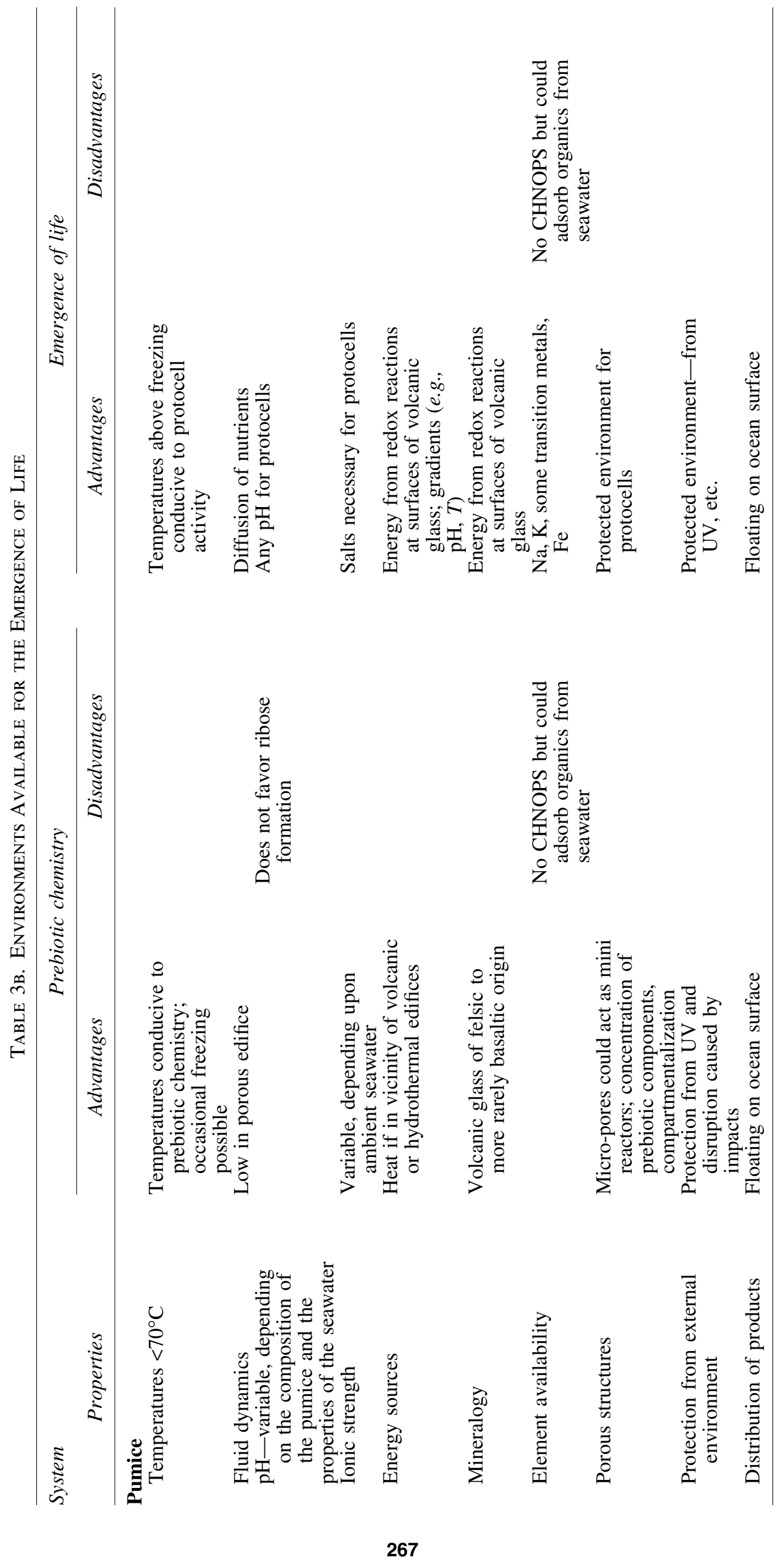




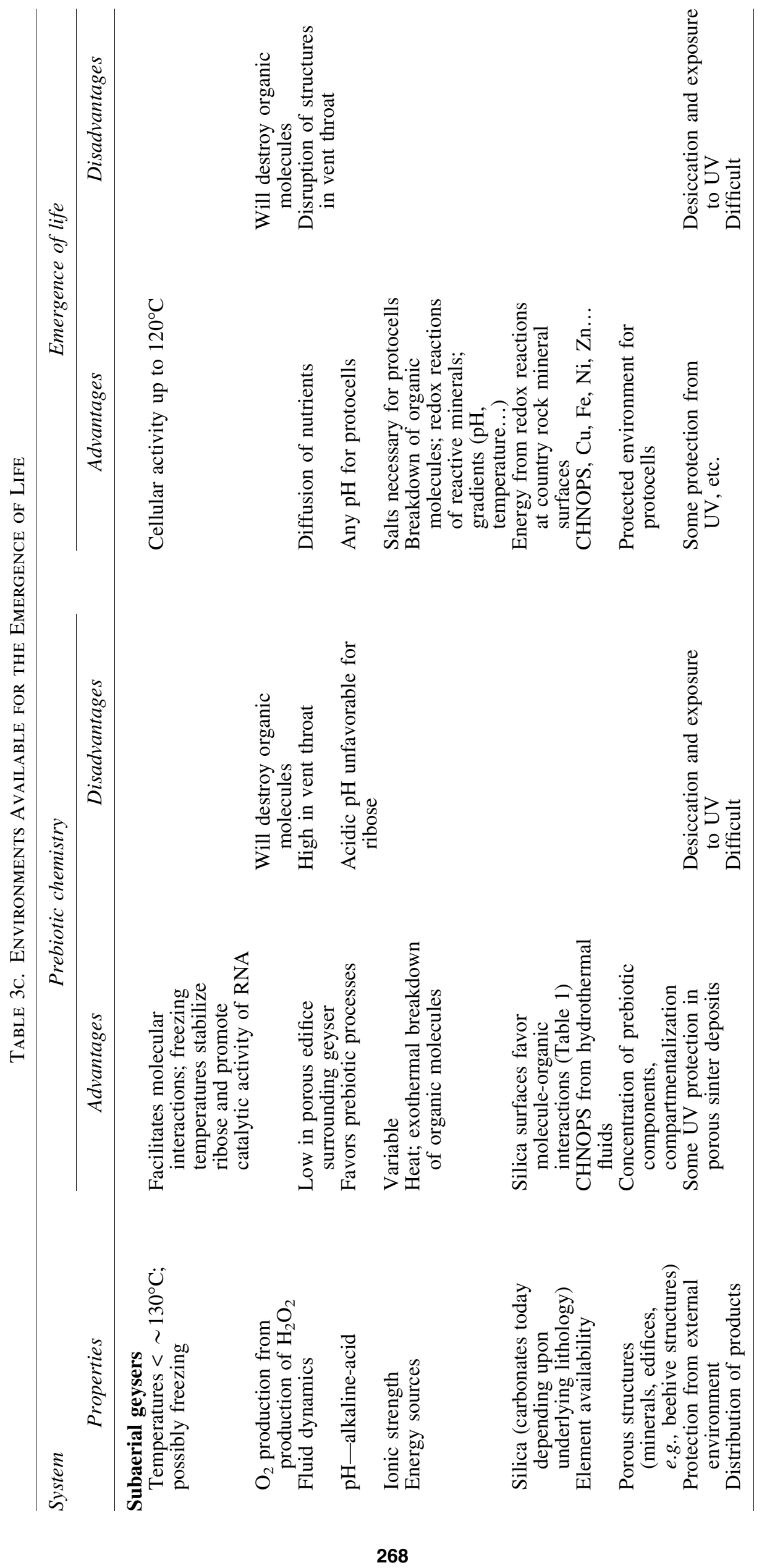




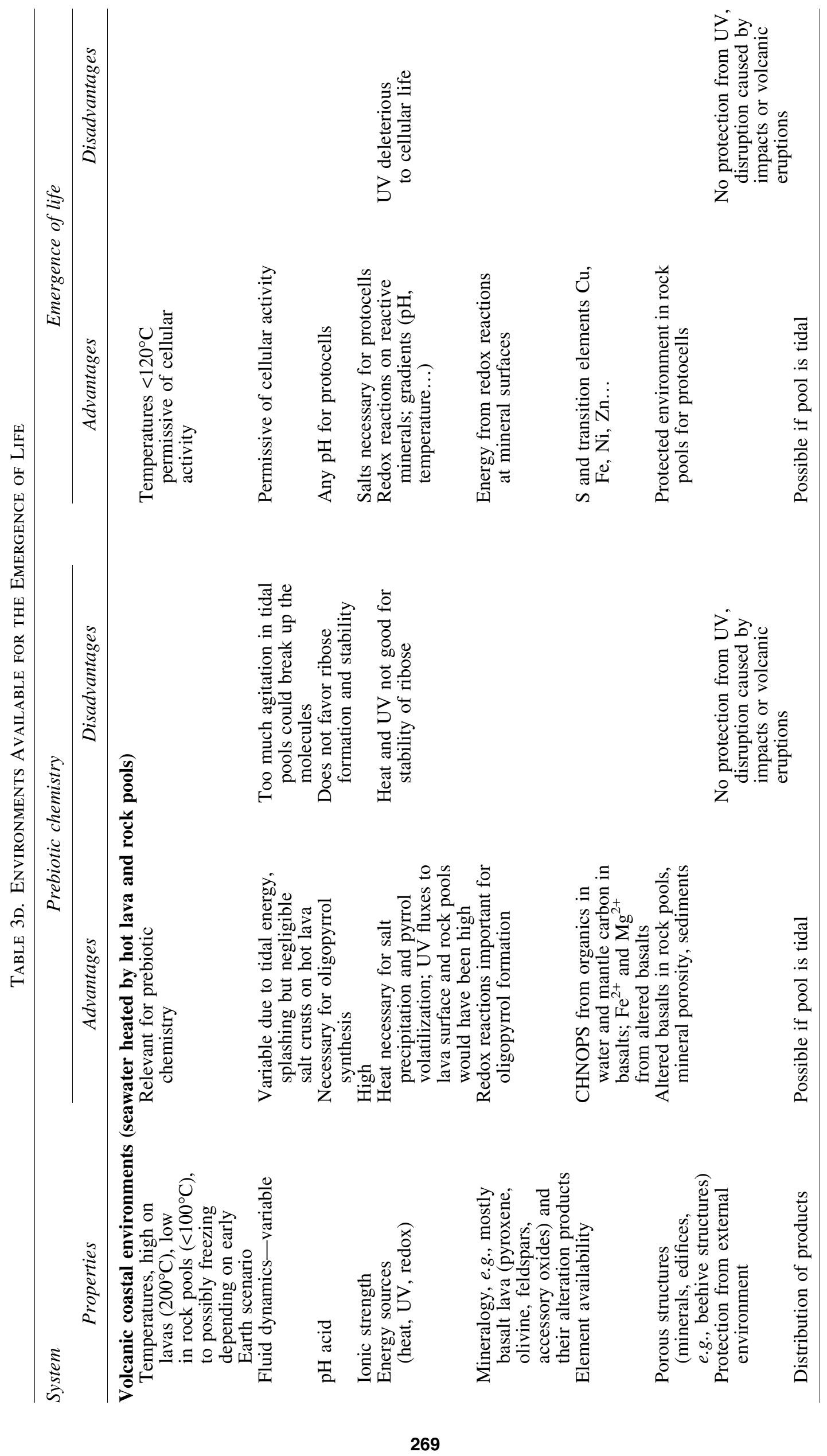


could lead to the assembly of more complicated biomolecules. This hydrothermal scenario for the origin of life has been supported by many others, for example Wächtershäuser (1988) and Holm and Charlou (2001).

Hydrothermal vents are characterized by a number of specific physicochemical properties (Table 3a), which make them a favorable environment for prebiotic processes and possibly the emergence of life. High heat flux through the crust of early Earth (Kamber, 2015; Van Kranendonk et al., 2015) suggests that hydrothermal activity would have been more widespread than at present. Fluid temperatures in modern hydrothermal vents are variable: up to $>400^{\circ} \mathrm{C}$ for acidic fluid effluent from black smokers clustered atop oceanic spreading ridges (von Damm, 1990; von Damm et al., 2003) to lower temperatures of $40-70^{\circ} \mathrm{C}$ for alkaline fluids issuing from more distal, off-ridge axis, white smokers (Kelley et al., 2001). The greater heat flow in the Hadean crust may have produced temperature conditions too hot for the existence of white smoker-type vents (Sleep, 2000; Zahnle et al., 2007).

The indigenous heat of hydrothermal systems and the heat produced by exothermic chemical reactions, including redox reactions occurring at the surfaces of reactive minerals within the hydrothermal vent edifices, are potential energy sources for prebiotic reactions occurring within the hydrothermal systems, as well as for primitive protocellular metabolisms. In prebiotic chemistry, we cannot define a temperature limit; nevertheless, there is competition between formation of a molecule and its destruction by hydrolysis. To displace equilibrium toward the formation of products, it is considered that the temperature would have to have been below $150^{\circ} \mathrm{C}$. Moreover, at temperatures above $120^{\circ} \mathrm{C}$ the breakup of critical biomolecules, such as RNA, would have occurred (Kashefi and Lovley, 2003). We suggest, therefore, that temperatures must have been below $120^{\circ} \mathrm{C}$ to allow the accumulation of critical biomolecules.

In terms of fluid dynamics, within the vent throat itself, high Reynolds number flows (i.e., turbulent flows) create flow instabilities, which would not encourage long-term mixing; however, within the porous hydrothermal structures themselves, turbulence would be much reduced. Hydrothermal fluids contain salts and organic molecules, essential for both prebiotic chemistry and for primitive metabolisms (Holm and Charlou, 2001; Pizzarello and Shock, 2010). The hydrothermal fluids interact with mafic and ultramafic rocks and their alteration products, as well as precipitate sulfide minerals, the reactive surfaces of which favor organicmineral interactions that affect concentration, structural conformation, stabilization, and complexification of molecules (e.g., Wächtershäuser, 1988; Russell and Hall, 1997). Hydrothermal edifices have the additional attribute that they are porous, their small cavities providing the possibility for the concentration of prebiotic components and eventual compartmentalization. Being submarine features, they provide protection from external stresses such as UV radiation and, to a certain extent, impacts that could destroy prebiotic molecules. Finally, submarine hydrothermal fluid effluent could have promoted the distribution of prebiotic products into seawater.

Russell and Arndt (2005) envisaged for the Hadean a situation similar to that of the present day, with active modern-style plate tectonics driving hot $\left(\sim 400^{\circ} \mathrm{C}\right)$ hydrothermal vents on top of spreading ridges and cooler $\left(\sim 40^{\circ} \mathrm{C}\right)$ vents occurring off-axis. However, given the different composition and rheology of the Hadean crust, plate tectonics in the modern fashion had probably not evolved in the Hadean era ( $c f$. Breuer and Spohn, 1995; Kamber, 2015). Nevertheless, as a result of abundant volcanic activity driven by high heat flow (Sleep, 2000; Zahnle et al., 2007), it is likely that hydrothermal cycling in the crust of the Hadean Earth was vigorous.

1.3.2. Pumice rafts. Brasier et al. (2011, 2013) proposed rafts of pumice floating in the ocean as a location for the origin of life. Pumice has a number of properties that are favorable to prebiotic processes (Table 3b). Pumice can be described as a "frothy" type of lava formed during explosive volcanism that has a typically acidic composition with a high degree of silica polymerization (andesitic to rhyolitic) composition and, more rarely, a basic (basaltic) composition in which silica is less polymerized. During the Hadean, the crust had a primarily basaltic composition (Kamber, 2015); thus the volume of pumice produced during this period was likely small. We note, however, that some local felsic volcanism is recorded in Paleoarchean formations (e.g., Lanier and Lowe, 1982; Lowe and Byerly, 1999; de Vries et al., 2010), in which there is evidence for pumice (Westall et al., 2006b; Brasier et al., 2013). Although mostly composed of volcanic glass, pumice today contains small amounts of minerals, such as feldspar, pyroxene, amphibole, and zircon. Secondary minerals, for example zeolites, may be deposited in its cavities by percolating water. Pumice can also adsorb metals, organics, and phosphates, as well as host organic catalysts, such as zeolites and titanium oxides. As floating objects at the atmosphere-ocean interface, the temperature ranges experienced by pumice rafts are lower than those at subsea hydrothermal vents, with maximum temperatures probably not exceeding $70^{\circ} \mathrm{C}$. During the Hadean, however, temperatures may even have been briefly freezing ( $c f$. Russell and Arndt, 2005), and the gradients between the pumice and the surrounding Hadean seawater would have been very small, perhaps no more than several degrees. $\mathrm{pH}$ values in the pumice cavities can be variable, depending upon the original composition of the rock and the properties of the seawater permeating it. Ionic strength of the permeating fluids would be variable, depending upon the salt content of the seawater and the effects of subaerial desiccation (rafts of pumice can be "stranded" in the shallowwater tidal environment, permitting dehydration). Energy sources for prebiotic reactions could have been provided by heat, if the pumice rafts were in the vicinity of volcanic or hydrothermal activity, and possibly from ambient UV photolysis, although the mineral structure would act as protection against UV radiation. Pumice, per se, does not contain any native reduced carbon, although a small component of mantle origin might be envisaged. It can, however, naturally absorb organic carbon and phosphate (Brasier et al., 2013). Titanium oxide and zeolite coatings within the vesicles are known catalysts in industrial processes (Brandes et al., 1998; Brito et al., 2004). Thus, where flushed perhaps by hydrothermal fluids in shallow-water settings, organic molecules could penetrate into the porous rock. The small, interconnected pores, on the order of microns to millimeters, 
could provide natural reaction flasks for the complexification of prebiotic molecules, which could continue over the long life span of the pumice clast (Brasier et al., 2011). The rock would protect products of processes occurring in the pores from UV radiation, and the very low density of pumice could help protect it during impact events by simply floating away from disturbance under the shock force or even ejection into the atmosphere to be redeposited elsewhere. Indeed, save for its volumetrically limited, and probably localized, generation, pumice provides an excellent means of distributing prebiotic products throughout the ocean.

1.3.3. Subaerial geysers. Although most hypotheses for the origins of life have considered marine geological settings, an ever-increasing number of propositions for the origin of life in a terrestrial system are being considered (i.e., in an atmosphere that was anoxic). The characteristics of hot spring geysers are summarized in Table 3c. Geysers are ephemeral subaerial hydrothermal vents around which fluids deposit minerals and mineraloids dictated by the composition of the underlying formations, through which the heated subsurface water rises. For example, siliceous and carbonate deposits form at Yellowstone National Park, depending on the source of the fluids. On a largely basaltic Hadean Earth, the deposits from geysers would have been mainly siliceous in composition rather than carbonate, similar to siliceous sinters in Yellowstone, Iceland, Kamchatka, or New Zealand (Campbell et al., 2015, and references therein). Physical variations in vent-area hydrodynamics within subaqueous and subaerial environments produce stratiform, spicular, beaded, nodular, and columnar geyserite varieties (e.g., Walter et al., 1996; Braunstein and Lowe, 2001; Jones and Renaut, 2003; Hinman and Walter, 2005; Campbell et al., 2015). However, both ancient and modern sinter deposit textures are invariably strongly influenced by biology and thus constitute a compromised analogue to their Hadean precursors (e.g., Konhauser and Ferris, 1996; Jones et al., 2001; Jones and Renaut, 2003). Geyserites are rocks formed around high-temperature hot springs, the exiting water and steam exceeding the boiling point but cooling to ambient temperatures with distance from the vent (even to freezing in apposite environments). Water exiting the vents would be exposed to solar radiation, leading to hydrogen peroxide production (Wilson et al., 2000). On the anoxic Hadean Earth, peroxide would have oxidized organic molecules and thus potentially hindered prebiotic chemistry and cellular life, if the latter existed. Fluids in the vents themselves would have mixed vigorously and turbidly, but the intensity of mixing would have decreased away from the vent in the surrounding mineral deposits. $\mathrm{pH}$ values of the fluids are variable, ranging from alkaline to acidic (Cady and Farmer, 1996; Walter et al., 1996; Braunstein and Lowe, 2001; Hinman and Walter, 2005; Campbell et al., 2015); generally, the ionic concentration of the hydrothermal fluids depends on their interaction with the formations through which they pass (Rowe et al., 1973; Livo et al., 2007). Hydrothermal alteration of the underlying rock formation will produce a suite of alteration minerals. For example, at Yellowstone, the alteration mineral suite includes quartz, adularia, illite, sulfide, alunite, and kaolinite (e.g., Livo et al., 2007). By contrast, $\sim 3.5 \mathrm{Ga}$ springs from the Pilbara precipitated silica and barite (Djokic et al., 2017), perhaps approximating the Borate Springs of the Puga Valley, India.

Potential energy sources for prebiotic reactions stem from heat, exothermal organic breakdown, and possibly UV radiation, unless the location was sufficiently well protected by the mineral precipitate, while oxidation of organic matter, redox reactions (minerals from the country rock), and gradients in $\mathrm{pH}$ and temperature could fuel primitive metabolisms. The elements essential for prebiotic chemistry and early life could have been made available through hydrothermal circulation in the crust (from either FischerTropsch-type synthesis or from fluid inclusions in ultramafic rocks; cf. Shock et al., 2002; McDermott et al., 2015) and eventually from recycled meteoritic carbon. Sulfur and transition metals could also be available for primitive metabolisms, depending upon the source rocks.

A number of reasons have been put forward for suggesting that subaerial environments are conducive to the emergence of life. Mulkidjanian and colleagues noted that the $\mathrm{K}^{+} / \mathrm{Na}^{+}$ratios of terrestrial freshwater fields are synonymous with those of modern cellular cytoplasm (Mulkidjanian et al., 2012a, 2012b; Dibrova et al., 2015). Deamer and Georgiou (2015) highlighted wetting-drying cycles, a characteristic repetitive process of modern terrestrial hot springs, as greatly enhancing the ability of these systems to concentrate and polymerize mononucleotides in the residual deposits of springs. These polymerized nucleotides could stabilize protocell membranes, control pore insertion that provides access to nutrients, and catalyze metabolisms (Damer and Deamer, 2015). Broadly, proponents of these systems note their lack of divalent cations relative to the oceans and suggest that their relatively small, well-bounded sizes increase the chance of concentrating prebiotic molecules; that is, they are, at times, more concentrated than oceans. Geyserproduced rocks have multiple surface heterogeneities (Walter et al., 1996; Jones et al., 2001, 2005; Campbell et al., 2015) that could provide mineral loci for the concentration of molecules during the drying stage of each wetting-drying cycle (Damer and Deamer, 2017). Moreover, the high presence of volatiles, for example ammonia, phosphorus, borate, and cyanide, facilitates polymerization of nucleotides by condensation reactions under the influence of solar energy (Mulkidjanian et al., 2003, 2012a; Dibrova et al., 2015).

Subaerial environments have attracted further attention for their possible sources of elements, such as boron and molybdenum, shown in the laboratory to help the formation of ribose, one of the key components of RNA (e.g., Benner et al., 2008). Benner's group (Neveu et al., 2013) thus consider boron-containing minerals and borate exposed at the Earth's surface, a situation considered by Grew et al. (2011) to be tectonically unlikely.

Another hypothesis by Ebisuzaki and Maruyama (2017) proposes a nuclear geyser model for the geological setting of the origin of life. This involves a geyser driven by a natural nuclear reactor, claimed to have been common on the Hadean Earth, due to the abundance of ${ }^{235} \mathrm{U}$ as nuclear fuel. The nuclear geyser supplies the following: (1) high-density ionizing radiation to promote chemical chain reactions; (2) a system to maintain the circulation of material and energy, which includes cyclical environmental conditions that enable 
the production of complex organic compounds; (3) a temperature lower than $100^{\circ} \mathrm{C}$ so as not to break down macromolecular organic compounds; (4) a locally reducing environment, which depends on the lithology exposed along the geyser wall; and (5) a container to confine and accumulate volatile chemicals. One major problem with this hypothesis is that such nuclear reactors, as are known from the geological record, could only have appeared after the oxidation of Earth about $2.4 \mathrm{Ga}$, since uranium can only be mobilized and concentrated in an oxidizing environment.

Although the porous structure of geyserite deposits could serve as protection from UV radiation, the flux of UV to early Earth was much higher than today (Cockell and Raven, 2004). These subaerial environments are also highly ephemeral. Consequently, the time permitted for the evolution, flourishing, and migration to the oceans of prebiotic molecules or cellular life (see Damer and Deamer, 2017) would likely have been very short. This temporal aspect is compounded by the fact that the surface environments that did exist would have been subjected to impacts from continued planetary accretion. Although there is debate about the reality of the hypothesized Late Heavy Bombardment (Ryder et al., 2000; Koeberl, 2006), which appears to have been more benign than previously supposed (Sleep, 2016; Zellner, 2017), it is clear that these high-energy impacts would have resulted in destruction of subaerial environments, even taking into account the fact that, since the Hadean-Archean Earth was largely an oceanic planet, subaerial environments would not have been very common, although it is likely they were continually renewed. Indeed, there is evidence only for rare emergent landmasses even at $\sim 3.5 \mathrm{Ga}$ (Van Kranendonk and Pirajno, 2004; Van Kranendonk, 2006; Westall et al., 2006b; Djokic et al., 2017); when extrapolated back to the early Hadean, such landmasses may not have been emergent, but rather evolving submarine "protocontinents" ( $c f$. Kamber, 2015).

1.3.4. Volcanic-hosted splash pools. Coastal volcanic environments have also been invoked as potential locations for the formation of biomolecules, such as photopigments (Fox and Strasdeit, 2013). Arguing that these kinds of environments would have been plausible for early Earth, Fox and Strasdeit (2013) imagined a stepwise scenario involving two different, but contiguous, environments: the condensation of amino acid-containing salts on hot lava to produce pyrrols, followed by the transport of pyrrols in vaporized seawater to cooler volcanic-hosted rock pools where they condensed and became oligomerized. Hydrochloric acid that formed in the acidic vapor was an important contributor, as were $\mathrm{Fe}^{2+}$ and $\mathrm{Mg}^{2+}$ ions liberated from acid-leached basalts that contributed to the formation of metal-oligopyrrols. Noting the high UV conditions (especially shorter UV wavelengths) prevalent on early Earth, Fox and Strasdeit (2013) underlined the importance of pigments in the protection of early cellular life. However, recent experiments have shown that prebiotic molecules, such as amino acids, have a low rate of survival in basaltic rocks containing ferrous iron when exposed to UV (dos Santos et al., 2016).

We have summarized the physicochemical characteristics of volcanic-hosted splash pool environments in Table $3 \mathrm{~d}$. Temperatures can range widely; they are high on the freshly erupted lavas and low in the rock pools, being even freezing if early Earth was frozen periodically. Fluid dynamics would be variable, low in the salt crusts on the hot lava and periodically high in the tidal splash pools, which could lead to disruption of molecular bonds. The $\mathrm{pH}$ would be low, necessary for oligopyrrol synthesis but not favorable for ribose formation. Ionic strengths in the salt crusts would be high. Energy would come from heat from the lava and UV flux to the surface of Earth, both potentially deleterious for life. Redox reactions at the surfaces of mafic/ultramafic minerals in the crust would have driven primitive metabolism. The mineralogy would be derived from the basaltic rocks, that is, pyroxene, olivine, feldspars, accessory oxides, and their alteration products (phyllosilicates, sulfides, etc.). The essential elements would have come from mantle organic compounds and organic compounds in the seawater, with $\mathrm{S}, \mathrm{Fe}^{2+}, \mathrm{Mg}^{2+}$, and other transition elements coming from the altered basalts. The salt crust would have provided a porous structure for compartmentalization of prebiotic minerals, as would the altered volcanic rocks in the rock pools. While the salt crusts could provide protection from UV (Cockell et al., 2010), protocells in the rock pools would probably be negatively affected by the UV flux on the Hadean Earth. The products formed in the pools would be distributed by tidal flow and splashing. These coastal environments, like the subaerial geysers, would have suffered from instability and impacts. Like all the aforementioned environments, they could have hosted certain prebiotic processes, but it is less likely that life appeared and flourished in such very short-lived rock pools.

\subsection{Summary of the geological context for the origin of life}

Above, we have summarized the very limited information available concerning the geological environments of the Hadean Earth ( $c f$. Russell and Arndt, 2005; Kamber, 2015; Van Kranendonk et al., 2015). The geological boundary between the Hadean and the Eoarchean was thought to be sharp and strongly influenced by the hypothesized Late Heavy Bombardment as well as tectonic overturn (Kamber, 2015). However, the recent suggestion of a period of prolonged bombardment between 4.2 and $3.4 \mathrm{Ga}$ rather than a short, sharp spike between 4.0 and 3.85 Ga (Zellner, 2017) might suggest a more gradual crustal evolution. We briefly described the different scenarios proposed for the emergence of life, ranging from subaerial springs (e.g., Mulkidjanian et al., 2012a, b), volcanic island coastal splash pools (Fox and Strasdeit, 2013), pumice rafts (Brasier et al., 2011, 2013), to submarine hydrothermal vents (Baross and Hoffman, 1985; Russell and Hall, 1997; Martin et al., 2008; Sleep et al., 2011; see also review in Dass et al., 2016) and addressed their significance with respect to what could have been the Hadean environment.

In the following, we describe another environment in which prebiotic chemistry could have occurred and life may have emerged: the layer of porous, volcanic, reactive sediments at the interface between mafic-ultramafic Paleoarchean crust and seawater. These processes involved the interaction of ubiquitous hydrothermal fluids with volcanic sediments charged with carbonaceous matter of multiple origins at scales ranging from outcrop- (point source venting) to microscopicscale infiltration of the porous sediments. This is a novel and 


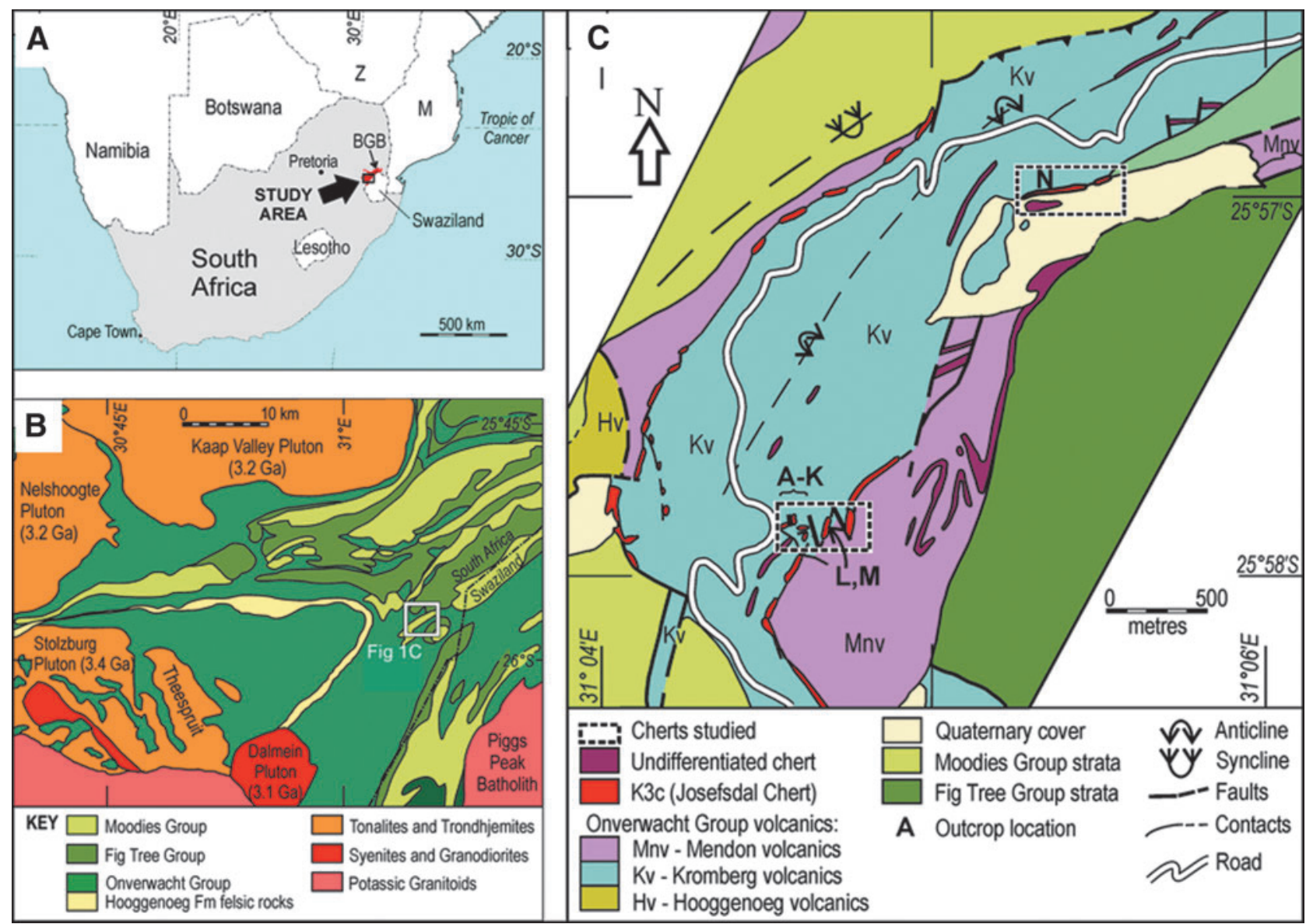

FIG. 1. (A) Location of the study area within South Africa. (B) General geological map of the Barberton Greenstone Belt showing location of the JC (white box). (C) Detailed geological map of the thin JC sediment exposures (red) within large thicknesses of mafic and ultramafic volcanics. Adapted from Westall et al. (2015a).

hitherto unrecognized phenomenon that we document in Early Archean $3.33 \mathrm{Ga}$ sediments from the Josefsdal Chert (JC), Barberton Greenstone Belt, South Africa (Fig. 1). Our observations describe field- to microscopic-scale phenomena, and we suggest that similar hydrothermal-sedimentary interface phenomena could have been common on the oceandominated Hadean Earth, despite possible differences in the global-scale geological situation between the Hadean and the Paleoarchean. Our observations thus add a new and significant spatial dimension to the geological setting of the complexification of the organic building blocks of life, a key progression in the evolutionary continuum leading to the origin of life itself.

\section{Early Earth Sediments and Hydrothermal Perfusion ${ }^{1}$}

\subsection{Sedimentology}

The Josefsdal Chert (JC) consists of several layers of volcanic sediments deposited in a shallow-water environment on top of basalt lava and covered again by basalt lava (Westall et al., 2015a). The sedimentary succession is divided into four facies representing sedimentation in shifting upper

\footnotetext{
${ }^{1}$ Note that information pertaining to materials and methods is in the appendix.
}

offshore to foreshore (beach) environments. Depending upon the environment of deposition, the sediments exhibit varying textures, grain size, and porosity (e.g., Fig. 2). Sediments deposited under a dynamic regime, for example storm conditions, are sand-sized $(63-500 \mu \mathrm{m})$, well-sorted, and porous. Sediments deposited in quiescent regimes are finer-grained, silt to fine sand-sized $(<100 \mu \mathrm{m})$, more poorly sorted, and less porous. Ashfall into quiet water environments produced graded layers of sand-sized grains $(>250 \mu \mathrm{m})$ to silt and fine detrital carbonaceous matter $(<63 \mu \mathrm{m})$ that were intermittently reworked into rippled structures by wind and tidal or current reworking (Fig. 2A).

The volcanic particles were altered to phyllosilicate (e.g., smectite) and anatase before silicification of the sediments (silicification explained below). This is demonstrated in Figs. $2 \mathrm{E}-2 \mathrm{~F}$ in which individual volcanic particles in the transmitted light micrograph (Fig. 2E) are shown to be composed of muscovite (pink color, the muscovite being the metamorphosed form of original smectite) or are outlined by anatase crystallites (blue) in the Raman mineralogical map in Fig. 2F. All were subsequently infiltrated and replaced to varying degrees by silica.

To observe incipient alteration phenomena on basalt particles, we exposed a mixture of crushed basalt and komatiite for 4 days at $50^{\circ} \mathrm{C}$ to analog Hadean seawater having an initial $\mathrm{pH}$ of 6.24 (Figs. 3-4). Even before alteration, the crushed volcanic 

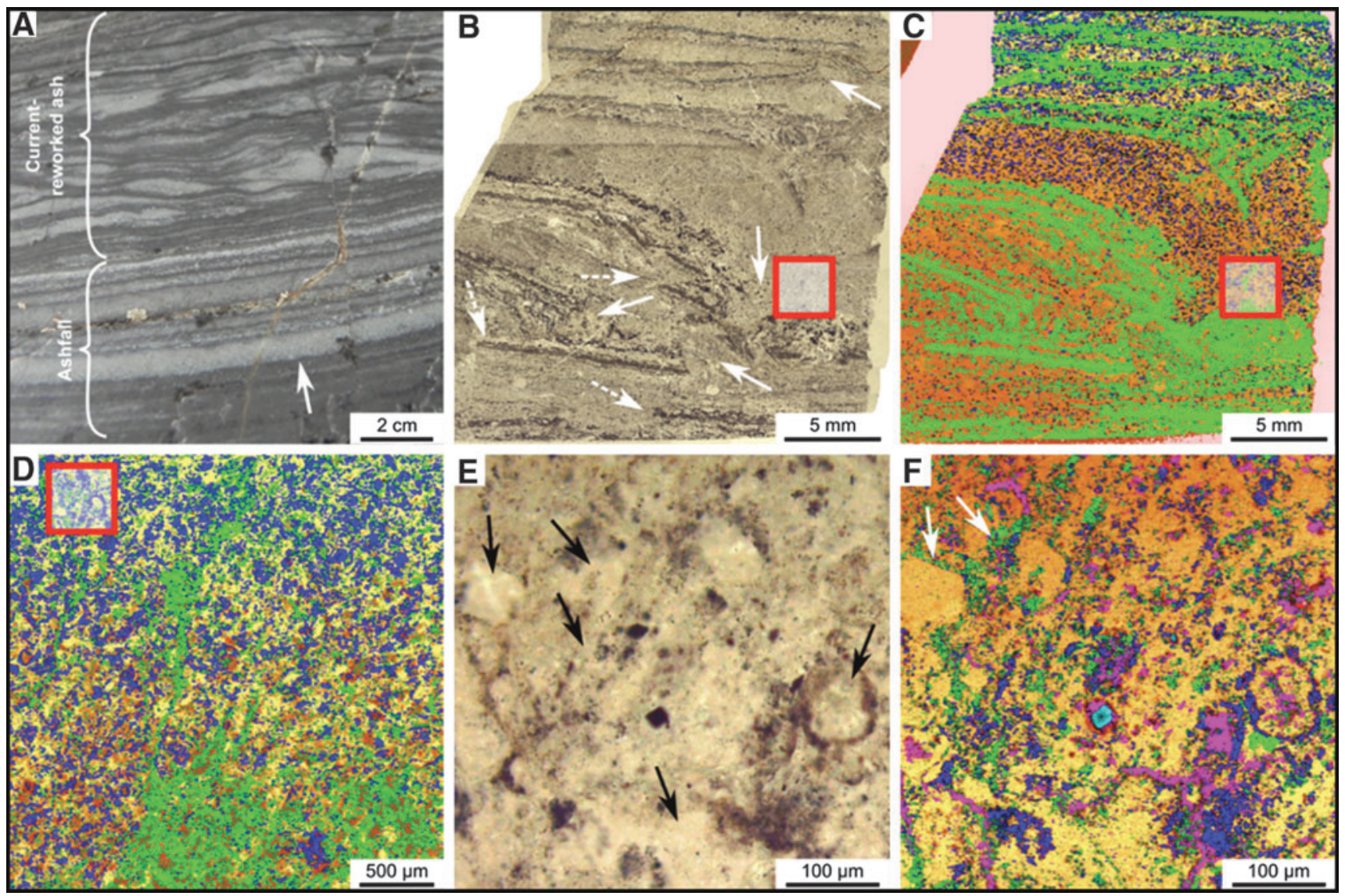

FIG. 2. Early Archean, laminated shallow marine volcanogenic sediments interacting with pervasive hydrothermal effluent from the $3.33 \mathrm{Ga}$ JC. (A) Field photograph of alternating ash (light) and carbonaceous (dark) layers. (B) Photomicrograph of a thin section from the same facies documenting layers disrupted, through soft sediment deformation, by infiltrating hydrothermal fluids (arrowed). Red box outlines detail in (D). (C) Raman map of (B), showing carbon (green) within the silicified matrix (orange, quartz); anatase (blue) represents altered volcanic clasts. Red box outlines details in (D). (D) Raman map (red boxes in B, C) showing carbon (green) intermixed with volcanic particles (represented by alteration phases: anatase, blue; muscovite, pink); the quartz matrix (yellow/orange) represents the silica precipitated by hydrothermal fluids. Optical image (E) and Raman map (F) are details of the red box in (D) showing carbon (green) coating volcanic particles (arrowed), which have been replaced by muscovite (pink), anatase (blue), and quartz (yellow/orange). Additional minerals: magnetite, light blue; rutile, red.

particles exhibited micron- to submicron-scale morphological heterogeneity, as documented in Figs. 3A-3B. During alteration in the slightly acidic seawater, there was an initial, rapid rise in $\mathrm{pH}$ from 6.24 to 7.4 within the sediments (red curve in Fig. 4A), which decreased gradually to equilibrium around 7.1. Alteration phenomena in the volcanic particles include the formation of pores 1-3 microns (Fig. 3C) and phyllosilicates (Fig. 3D). Figures 4B-4C, which show a former gas bubble in an altered pyroxene grain, document micron-scale cavities, depressions, and irregularities at its surface. These morphological heterogeneities are accompanied by similarly scaled elemental variations related to the diverse minerals exposed and altered on the particle surface. EDX elemental maps show two micron-scale phases; needle-shaped crystals of pyroxene (Na, $\mathrm{Mg}, \mathrm{Al}, \mathrm{Si}, \mathrm{Ca}$, trace $\mathrm{Fe})$ co-occurred with ilmenite $\left(\mathrm{FeTiO}_{3}\right)$.

\subsection{Evidence for hydrothermal activity}

Physical evidence for hydrothermal activity and infiltration of silica-rich hydrothermal fluids consisted of visible macroscopic- to microscopic-scale hydrothermal veins and confirmation of contemporaneous, lateral, and vertical infiltration of fluids under pressure into the sediments. Mineralogical evidence included pervasive silicification of the entire sedimentary deposit and secondary mineralization (alteration minerals, hydrothermally precipitated minerals, such as siderite). Geochemical evidence was revealed by bulk analyses and in situ elemental distribution.

2.2.1. Physical evidence. Contemporaneous and postlithification hydrothermal conduits and vents visible at the outcrop and the microscopic scale (Fig. 5) indicated point sources of fluid entry. Figure 5A shows a large, vertical, hydrothermal intrusion cross-cutting layers (almost invisible) of highly silicified hydrothermal sediments. Chert layers parallel to the bedding plane (dashed red outlined layers) represent the intrusion of pressurized hydrothermal fluids into partially lithified and still slightly deformable layers of volcanic sediments, provoking a swale-like undulating structure (as in the lowermost intrusion of Fig. 5A).

On the microscopic scale, Figs. 5B-5C document contemporaneous, forceful intrusion of hydrothermal fluids into 


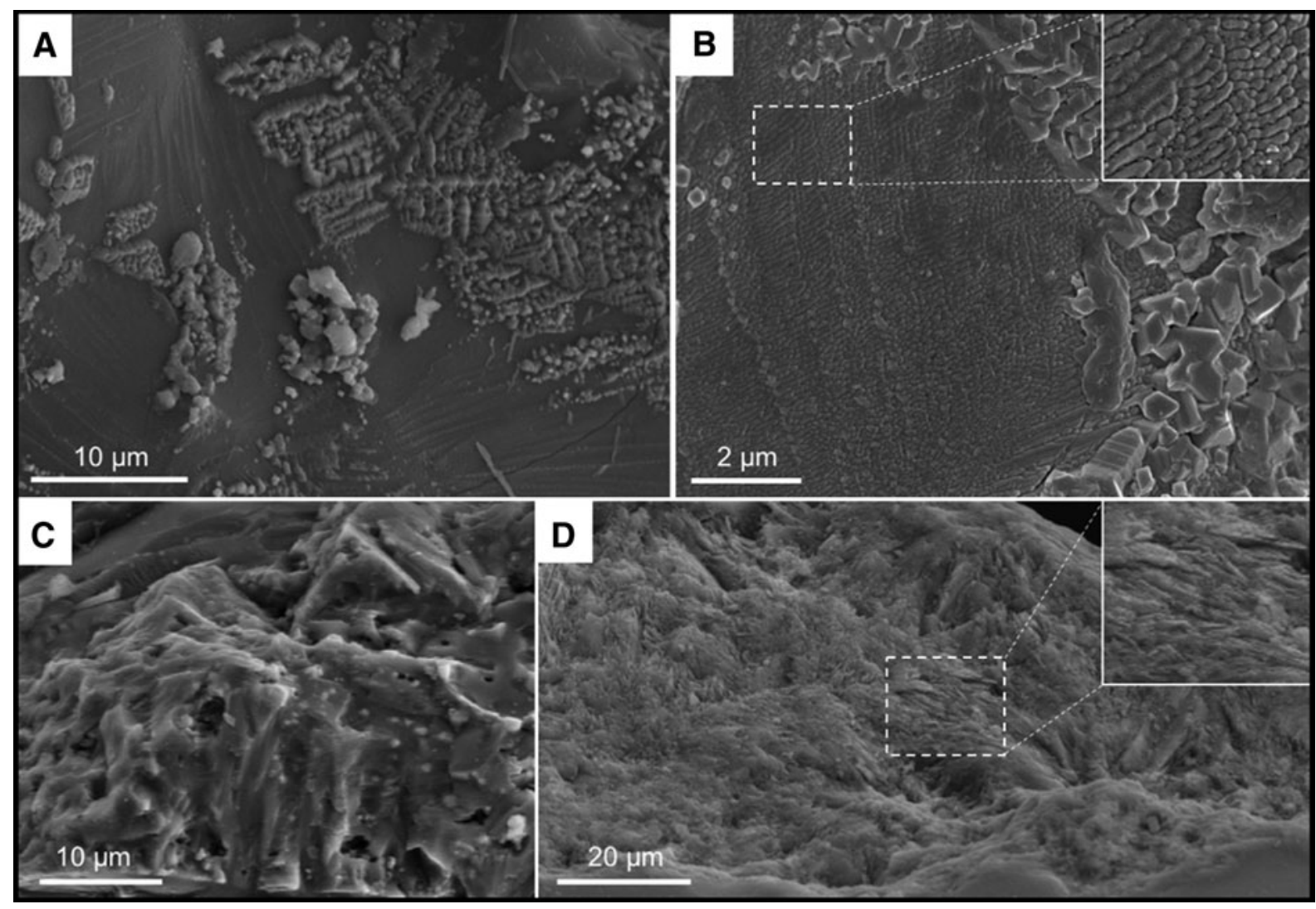

FIG. 3. Crushed volcanic rocks (mixture of East Pacific Rise basalt and komatiite) before and after corrosion in artificial seawater (starting $\mathrm{pH}=6.24$ ). (A) Scanning electron microscope view of the surface of basalt glass with skeletal pyroxene crystals showing mineralogical and morphological variability on the micron scale. (B) Detail of the volcanic glass surface (with inset) documenting submicron-scale morphological heterogeneity. (C) Sample from the same crushed volcanic rocks after 15 days of corrosion (ending $\mathrm{pH}=7.1$ ). The pyroxene crystals show pits and pores ranging in size from submicron to a few microns. (D) Phyllosilicate-coated surface of a volcanic glass shard corroded for 15 days $(\mathrm{ending} \mathrm{pH}=7.1$ ).

cohesive but not lithified, fine-grained sediments. The borders of the intrusion are not straight, as would be the case in brittle, post-lithification intrusion (e.g., the large vertical vein crosscutting the sediments in Fig. 5A), but rather are irregular and slightly blended with the surrounding sediments. The miniature intrusive feature broadens toward a bedding plane surface and terminates at the surface in a funnel-shaped exit structure (microscopic vent). The hydrothermal fluids in this vein transported reduced carbon (see Raman map in Fig. 5C), which was both deposited on the walls of the vein and expulsed with hydrothermal fluids into the seawater where it was deposited as floccular structures within the sediment (not shown).

Figures 2B-2D document mixing of internal layers of the volcanic sediments by fluids under pressure. The sediment layers, outlined in black, were disrupted and mixed (Fig. 2B, white arrows) as highlighted in the Raman mineralogical maps (Figs. 2C-2D). On a scale of millimeters to microns, carbonaceous layers (colored green in Fig. 2) are thoroughly mixed with the groundmass representing altered (pseudomorphed) volcanic grains (blue for anatase and yellow for quartz) in a quartz matrix (yellow to orange).

2.2.2. Mineralogical evidence. The top of the hydrothermally intruded outcrop in Fig. 5A is characterized by parallel layers of light-colored, nearly translucent silica. While some of the layers represent penecontemporaneous lateral intrusions of hydrothermal fluids into semi-lithified sediment, other layers display microscopic textures that suggest deposition as a chemical sediment, that is, as a silica gel (Fig. 6). Compositionally, the translucent chert consists of silica and carbon only, with no evidence for detrital volcanic input (see Raman maps in Figs. 6C-6D). This sediment consists of several layers exhibiting different textural and depositional characteristics. Highlighted in the red box in the central part of the scanned thin section in Fig. 6A, and enlarged in Fig. 6B (with accompanying Raman map, Fig. 6E), is a portion of the sediment in which a finely laminated layer lies beneath a mottled layer. Very fine layers of carbon outline the lower part of the sedimentary layering; the conformity of the layer indicates passive settling. These sediments are matrix-supported, that is, supported by silica. The top of the fine sedimented layers, on the other hand, consists of a packet of thin wrinkly layers of carbon (red arrows in Figs. 6B-6C) that are subparallel to the sediment bedding planes and show cohesive behavior and plastic deformation in the form of tear and roll-over structures (dotted black arrows in Figs. 6B-6C). Following the interpretations of Westall et al. (2015a), the packet of wrinkly layers represents a silicified phototrophic biofilm 


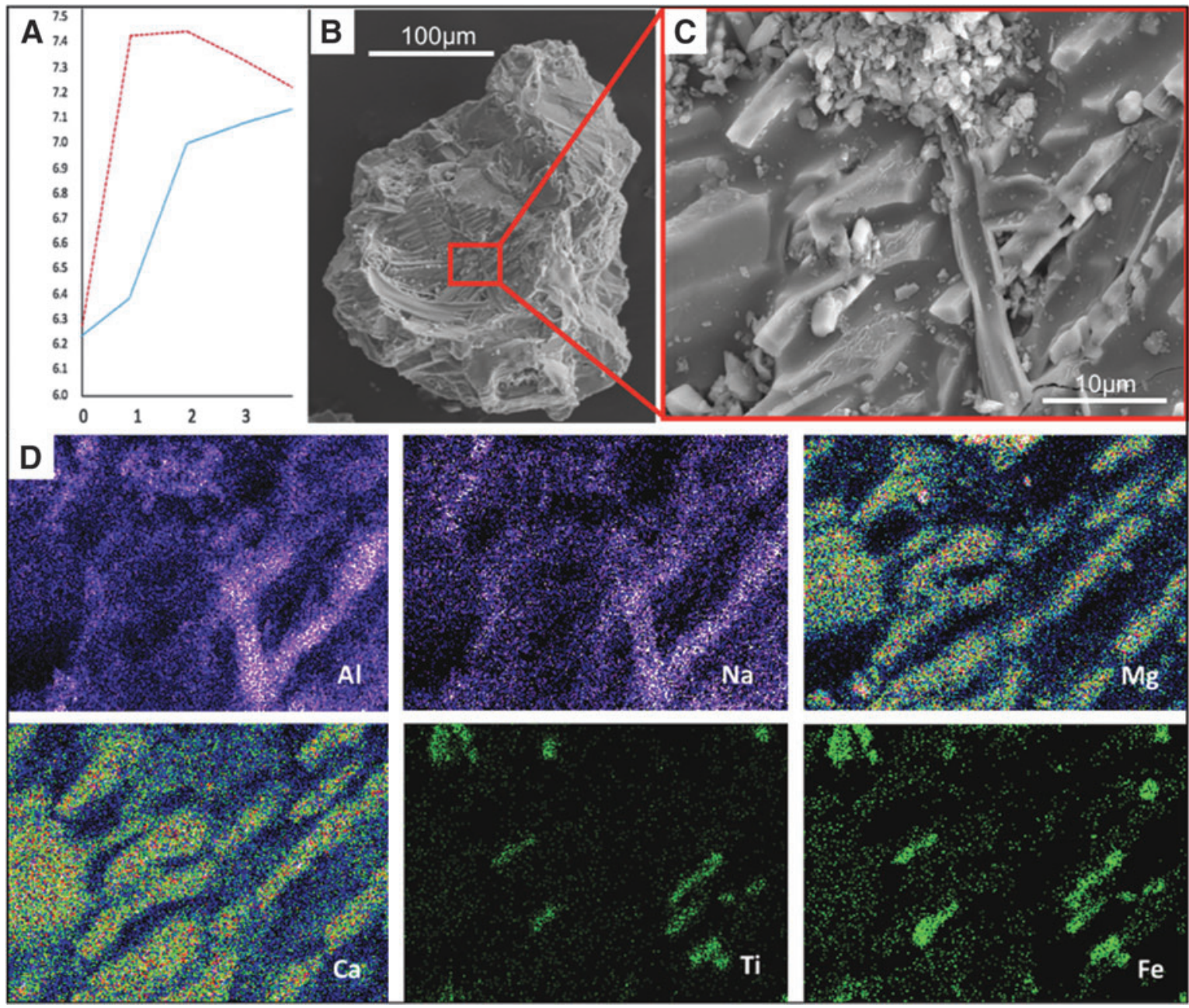

FIG. 4. Corroded volcanic grains from a mixture of East Pacific Rise basalt and komatiite (as in Fig. 3). (A) Changing pH during the first 3 days of corrosion of a mixture of East Pacific Rise basalt and komatiite in artificial seawater with a starting $\mathrm{pH}$ of 6.24. The red curve denotes $\mathrm{pH}$ changes in the sediment, blue curve changes in the overlying seawater. The rapid change in $\mathrm{pH}$ to more alkaline conditions from an initial weak acid is ascribed to the reaction of this seawater with particularly reactive minerals in the volcanic grains; the $\mathrm{pH}$ gradient in the pore spaces of volcanic sediment can thus be initiated in days. (B, C) Scanning electron micrographs of an ex-gas bubble in a pyroxene grain, documenting variable surface textures including porosity and protrusions associated with compositional variability (D). (D) EDX elemental maps showing two main phases: needle-shaped crystals of pyroxene $(\mathrm{Na}, \mathrm{Mg}, \mathrm{Al}, \mathrm{Ca}$, trace $\mathrm{Fe}$; Si not shown) co-precipitated with ilmenite $(\mathrm{FeTiO})$.

(nota bene, for the purposes of this paper, the origin of the carbonaceous matter-biogenic or abiogenic — in the Josefsdal sediments is irrelevant; of importance here is the documentation of the interaction between hydrothermal fluids and carbonaceous sediments).

Above the torn biofilm is a chaotic layer of mixed carbonaceous clots and torn fragments of the underlying phototrophic biofilm, again in a matrix-supported siliceous sediment. The association of the chaotic layer with evidence of physical deformation of the phototrophic biofilm suggests turbulent flow. Adjacent to the sampling location is a growth fault (not shown) which appears to have been the conduit for the hydrothermal fluids that deposited as a silica gel-like sediment on top of the immediately surrounding sedimentary surfaces at the same time as laterally penetrating, partially lithified sediments in bedding-parallel, silllike intrusions. Precipitation of silica as a gel from supersaturated hydrothermal fluids that form a chemical sediment has previously been suggested for rocks of a similar age and appearance from the Onverwacht Group by Ledevin et al. (2014).

Silicification, which occurred on timescales ranging from contemporaneous to early diagenetic to late diagenetic, provides further evidence for hydrothermal influence on the JC sediments. Penecontemporaneous silicification is documented by soft-sediment deformation due to intruding silica-rich fluids, as shown in Fig. 2B, and documented in Westall et al. (2015a) by fossilization of a living, in situ phototrophic biofilm by silica (Westall et al., 2006a, 2011). Partial to total replacement of the altered volcanic particles by silica (Figs. 2E-2F, black arrows; Fig. 6) took place rapidly as indicated by the lack of compaction of any of the particles, especially the plastically deformable ones, such as carbonaceous clots. Silicification of the sediments would have occurred through the precipitation of silica gel in the pore spaces from silica-enriched fluids (i.e., seawater mixed 

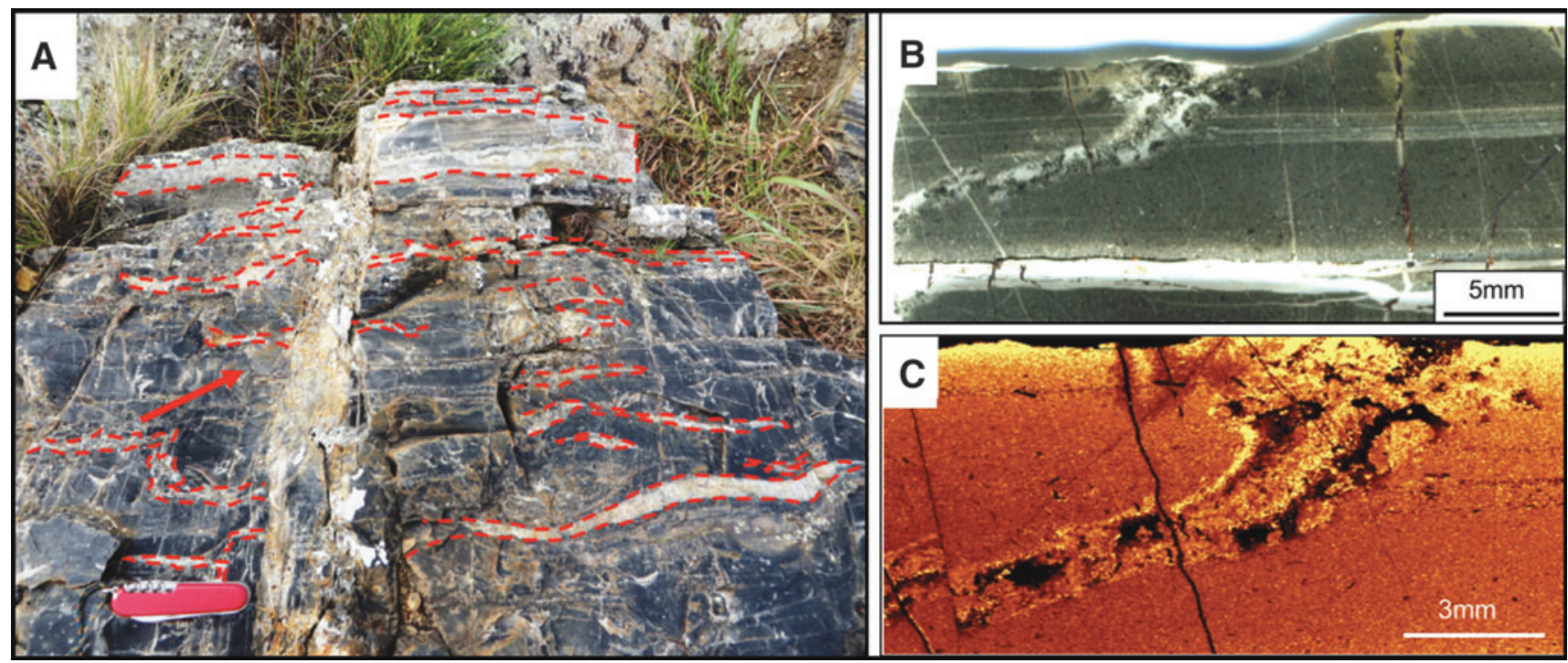

FIG. 5. Macroscopic to microscopic hydrothermal veins. (A) Late diagenetic, vertical hydrothermal vent (full arrow) cross-cutting hummocky-swaley storm deposits in the JC (Facies A of Westall et al., 2015a). Note also infiltrations of hydrothermal chert, emanating from the central vent, parallel to the sediment layering (outlined by dotted red lines). (B) At the thin-section scale, this optical micrograph shows a hydrothermal veinlet cross-cutting finely laminated, fine-grained sediments. (C) Raman map of carbon distribution in the sediment and in the vein shown in B); brighter color indicates higher concentration, i.e., carbon is at its highest concentration when entrained within the vein.

with hydrothermal silica and pore waters infiltrated by silica-rich hydrothermal fluids).

The lower layers of the JC, stratigraphically just above the underlying basalt, are more highly silicified (up to $99 \%$ $\mathrm{SiO}_{2}$ ) than the upper layers (up to $96 \% \mathrm{SiO}_{2}$ ), with the variable degree of silicification being observable at outcrop scale. The lower JC layers appear black, and their sedimentary structures are almost completely obfuscated owing to the very significant degree of silicification. In these layers, the rocks are also suffused by myriad small to large,
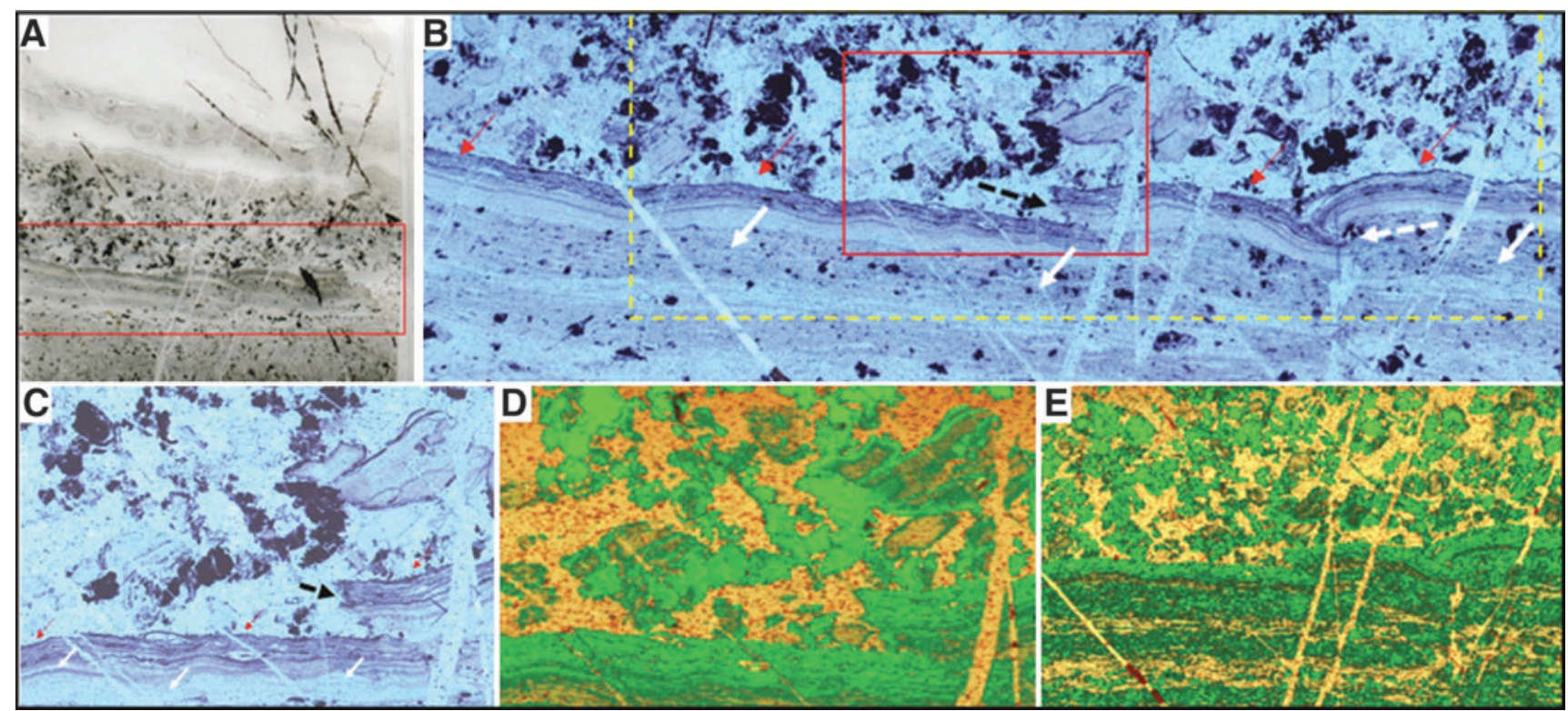

FIG. 6. Silica gel-like sediment from the $3.33 \mathrm{Ga}$ JC. (A) Scanned thin section slide of a deposit of hydrothermal silica containing carbonaceous clots and layering. (B) Detail of red box in (A) showing fine-scale carbonaceous layering in the lower part of the image and a mottled carbonaceous texture in the upper part. The top of the layered section shows plastic deformation (dashed white arrow) and tearing, indicative of disruption by the dynamic flow of hydrothermal fluids. Red arrows indicate the cohesive layer above the plastically deformed layer, and solid white arrows indicate detrital sedimentation below. The red box denotes the detail in (C) and the Raman scan in (D), while the yellow box denotes the area of the Raman map in (E). (C) Detail showing tearing of the cohesive surface of the finely laminated layer (black arrow). (D, E) Raman maps demonstrate that the sample consists of only quartz (yellow-orange) and carbon (green). 
late-stage hydrothermal silica veins. Toward the top of the outcrop, although the silica contents are still high (up to $96 \%$ ), the sedimentary structures are perfectly preserved and readily visible, while late-stage hydrothermal veins are rarer (Fig. 5A)

Siderite is co-precipitated with the silica in the finergrained, more poorly sorted sediments close to hydrothermal vents and in contemporaneous hydrothermal veins themselves. Co-precipitation with silica is indicated by the fact that siderite is the only mineral phase not to be silicified (Figs. 7C-7E). The precipitation of siderite crystals stands testament to an environment infused with $\mathrm{CO}_{2}$, having a high inorganic carbon content, and variable $\mathrm{pH}$, as modeled in Table 4 .

A diagenetically precipitated silica matrix that rapidly sealed and lithified all components and signatures in the JC, leading to final observed precipitation, was finally preserved by rapid diagenetic sealing and lithification by a precipitated silica matrix (van den Boorn et al., 2007; Sugitani et al., 2015; Westall et al., 2015a; Tartèse et al., 2017). Rapid diagenetic sealing prevented later elemental composition changes.

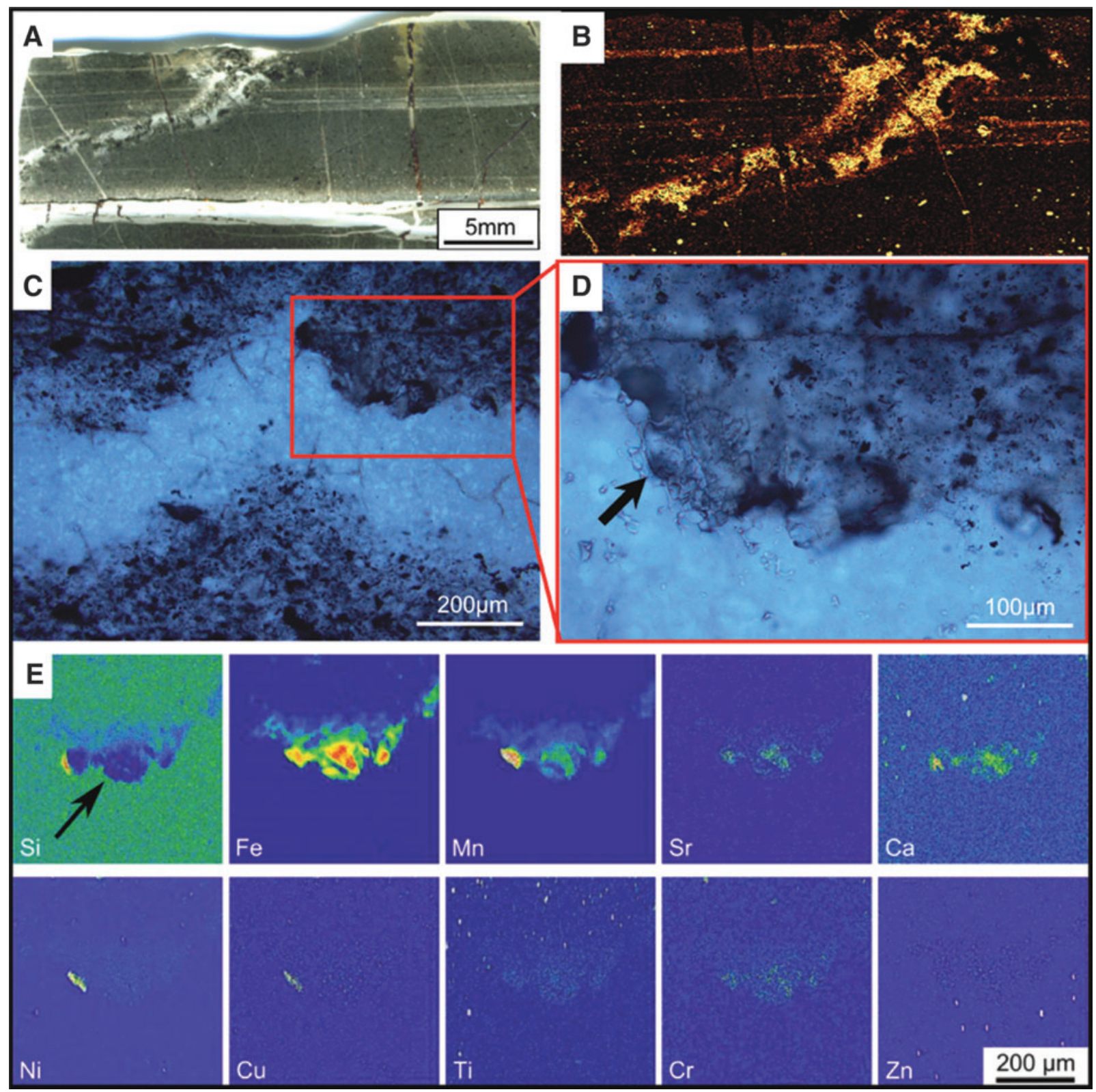

FIG. 7. Hydrothermal veinlet in fine-grained carbonaceous sediments from Josefsdal. (A) Optical micrograph showing a hydrothermal veinlet cross-cutting finely laminated, fine-grained sediments. (B) Raman map of the siderite distribution in the sediment and in the veinlet; brighter color indicates higher concentration. (C, D) Optical micrograph views of a siderite $\left(\mathrm{FeCO}_{3}\right)$ and rhodochrosite $\left(\mathrm{MnCO}_{3}\right)$ co-precipitate at the edge of the veinlet shown in $(\mathrm{A})$. Red box in $(\mathrm{C})$ shows location of detail in (D). Arrow in (D) points to the same location as the arrow in (E). (E) PIXE elemental maps (beam size: $2 \mu \mathrm{m}$; map size: $500 \times 500 \mu \mathrm{m}$; resolution: $256 \times 256$ pixels; $11 \mathrm{~h}$ acquisition time) of area denoted by red box in (C) document concentrations of other elements associated with the siderite/rhodochrosite precipitation, including $\mathrm{Mn}, \mathrm{Sr}, \mathrm{Ca}, \mathrm{Ni}, \mathrm{Cu}, \mathrm{Ti}$, $\mathrm{Cr}$, and $\mathrm{Zn}$ scavenged from the hydrothermal fluids. 
Table 4. Results of the PHREECQ-Modeled Runs for Mineral Precipitation IN HaDean SEawater

\begin{tabular}{lccccccc}
\hline $\mathrm{PCO}_{2}$ & $T(\mathrm{C})$ & Final $\mathrm{pH}$ & {$[\mathrm{Ca}]_{T}(\mathrm{~m} / \mathrm{L})$} & {$[\mathrm{Fe}(\mathrm{II})]_{T}(\mathrm{~m} / \mathrm{L})$} & SI (calcite) & SI (siderite) & Model \\
\hline 1.0 & 50 & 7.99 & $5.02 \mathrm{E}-04$ & $1.10 \mathrm{E}-07$ & 1.01 & -1.29 & 1 \\
3.2 & 50 & 7.70 & $6.55 \mathrm{E}-04$ & $3.29 \mathrm{E}-07$ & 1.1 & -1.04 & 1 \\
10.0 & 50 & 7.44 & $9.48 \mathrm{E}-04$ & $9.55 \mathrm{E}-07$ & 1.19 & -0.83 & 1 \\
100.0 & 50 & 7.04 & $2.14 \mathrm{E}-03$ & $6.10 \mathrm{E}-06$ & 1.42 & -0.43 & 1 \\
1.0 & 100 & 7.08 & $5.18 \mathrm{E}-05$ & $5.93 \mathrm{E}-07$ & -0.41 & -0.59 & 1 \\
3.2 & 100 & 6.81 & $5.35 \mathrm{E}-05$ & $1.68 \mathrm{E}-06$ & -0.41 & -0.37 & 1 \\
10.0 & 100 & 6.56 & $5.44 \mathrm{E}-05$ & $4.60 \mathrm{E}-06$ & -0.47 & -0.17 & 1 \\
100.0 & 100 & 6.14 & $5.37 \mathrm{E}-05$ & $2.99 \mathrm{E}-05$ & -0.68 & 0.18 & 1 \\
1.0 & 50 & 7.28 & $2.85 \mathrm{E}-06$ & $1.87 \mathrm{E}-06$ & -1.37 & -0.7 & 2 \\
3.2 & 50 & 7.12 & $3.86 \mathrm{E}-06$ & $3.98 \mathrm{E}-06$ & -1.3 & -0.54 & 2 \\
10.0 & 50 & 7.00 & $5.88 \mathrm{E}-06$ & $7.73 \mathrm{E}-06$ & -1.14 & -0.35 & 2 \\
100.0 & 50 & 6.87 & $9.25 \mathrm{E}-06$ & $1.78 \mathrm{E}-05$ & -0.84 & 0.05 & 2 \\
1.0 & 100 & 6.74 & $5.38 \mathrm{E}-05$ & $2.24 \mathrm{E}-06$ & -0.43 & -0.31 & 2 \\
3.2 & 100 & 6.54 & $5.44 \mathrm{E}-06$ & $4.98 \mathrm{E}-06$ & -0.48 & -0.16 & 2 \\
10 & 100 & 6.36 & $5.45 \mathrm{E}-05$ & $1.11 \mathrm{E}-05$ & -0.55 & -0.01 & 2 \\
100.0 & 100 & 6.04 & $5.39 \mathrm{E}-05$ & $5.10 \mathrm{E}-05$ & -0.75 & 0.29 & 2 \\
\hline
\end{tabular}

$\mathrm{T}=$ total concentration.

Model $1=$ Initial equilibration with atmospheric $\mathrm{CO}_{2}$ followed by equilibration with minerals.

Model 2 =Equilibration with $\mathrm{CO}_{2}$ and minerals simultaneously.

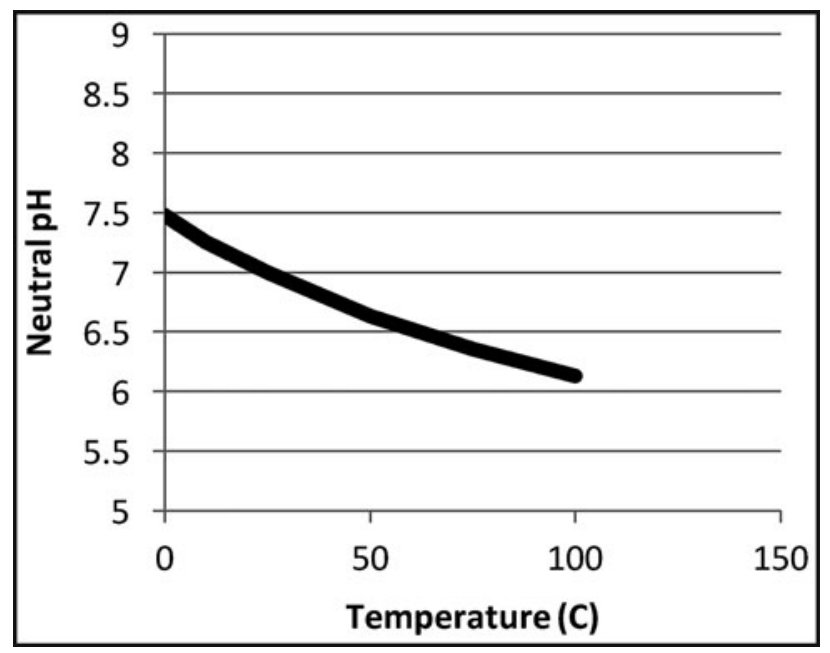

2.2.3. Geochemical evidence. Bulk geochemical analyses in Fig. 8A show shale-normalized (PAAS; McLennan, 1989) REE $+Y$ patterns of several samples from the JC (Fig. 8), documenting a positive Eu anomaly (Figs. 8A-8B), indicative of hydrothermal influence (Danielson et al., 1992; Derry and Jacobsen, 1999). In Fig. 8B, the plot of Eu and Ce ratios further refines the results by showing that, while the hydrothermal influence is very strong, there is also an admixture of seawater, with different samples showing different degrees of mixing (Danielson et al., 1992; Derry and Jacobsen, 1999). Finally, the particle-induced X-ray emission (PIXE) spectrum in Fig. 8C, from a strongly hydrothermally influenced JC sample (Facies C, Westall et al., 2015a), documents the presence of hydrothermally transported elements, including $\mathrm{Fe}, \mathrm{Ni}, \mathrm{Cu}, \mathrm{Zn}, \mathrm{As}$, and $\mathrm{Ba}$. The scavenging of this hydrothermal signature by carbonaceous material is demonstrated in Fig. 9. Furthermore, the incorporation of large amounts of $\mathrm{Ni}$ into early diagenetic pyrites of the $\mathrm{JC}$, from which up to $3 \mathrm{wt} \%$ may have been provided by hydrothermal circulation, additionally suggests the early diagenetic influence of hydrothermal fluids (Hubert, 2015).

\section{Discussion}

\subsection{A hydrothermal environment}

The above observations relating to the physical, mineralogical, and geochemical evidence for hydrothermal fluid influence on the JC sediments clearly show that hydrothermal fluids permeated the sediments during their deposition, mixed to varying degrees with the ambient seawater, formed chemical deposits, and continued interaction with the sediments from the early to late diagenetic phase.

3.1.1. Silica gels. A significant observation of this study relates to the importance of silica gels filling in pore spaces between the volcanic particles, as well as precipitating as chemical sediments. Silica gels are porous, granular deposits containing fluids inside nanosized pores. These silica gels fill and thereby preserve the pores in the sedimentary 


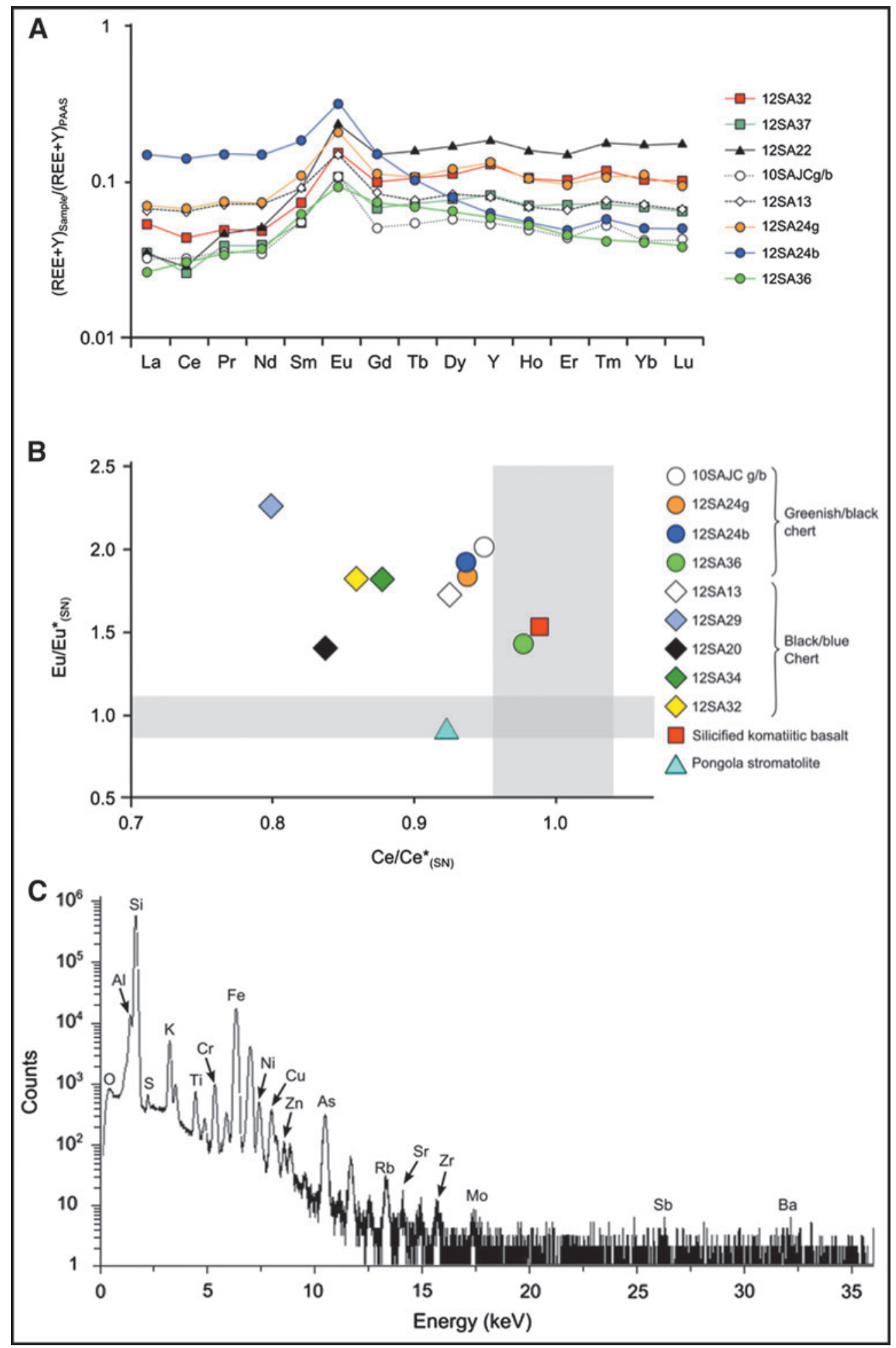

FIG. 8. Geochemical analyses demonstrating the bulk influence of hydrothermal fluids on the JC sediments (from Hubert, 2015). (A) Shale-normalized (PAAS, McLennan, 1989) REE+Y patterns of several samples from the JC. The positive Eu anomaly is indicative of a hydrothermal influence (Danielson et al., 1992; Derry and Jacobsen, 1999). (B) Plot of Eu and Ce anomalies (shalenormalized; PAAS, after McLennan, 1989). Eu/Eu*: Eu/((Sm*05) + (Gd*05)) and Ce/Ce*: Ce/((La*05) + (Pr*05)). An Eu/Eu* value (related to the Eu anomaly) of $>1$ indicates a hydrothermal signature (Danielson et al., 1992; Derry and Jacobsen, 1999), while $\mathrm{Ce} / \mathrm{Ce}^{*}$ (related to a La anomaly) indicates a strong marine signal where $<1$. The results from two additional samples, silicified carbonates of the $2.9 \mathrm{Ga}$ silicified stromatolites of the Pongola Supergroup, South Africa, and a silicified komatiitic basalt from Josefsdal are given for comparison. The Pongola stromatolite displays a marine signature $(\mathrm{Ce} / \mathrm{Ce} *<1$ plus La anomaly) but no hydrothermal signature, while the silicified basalt exhibits a hydrothermal signal (Eu/Eu* of $>1$ plus Eu anomaly) without marine influence. Josefsdal sediment samples show mixed signatures indicating fluids influenced by both marine waters and hydrothermal activity. (C) PIXE spectrum acquired for $8 \mathrm{~h}$ with a $2 \mu \mathrm{m}$ diameter proton beam from a hydrothermal chert vug in highly silicified Facies D sediments (after Westall et al., 2015a) showing the presence of a number of hydrothermally transported elements, including $\mathrm{Fe}, \mathrm{Ni}, \mathrm{Cu}, \mathrm{Zn}, \mathrm{As}$, and $\mathrm{Ba}$. 


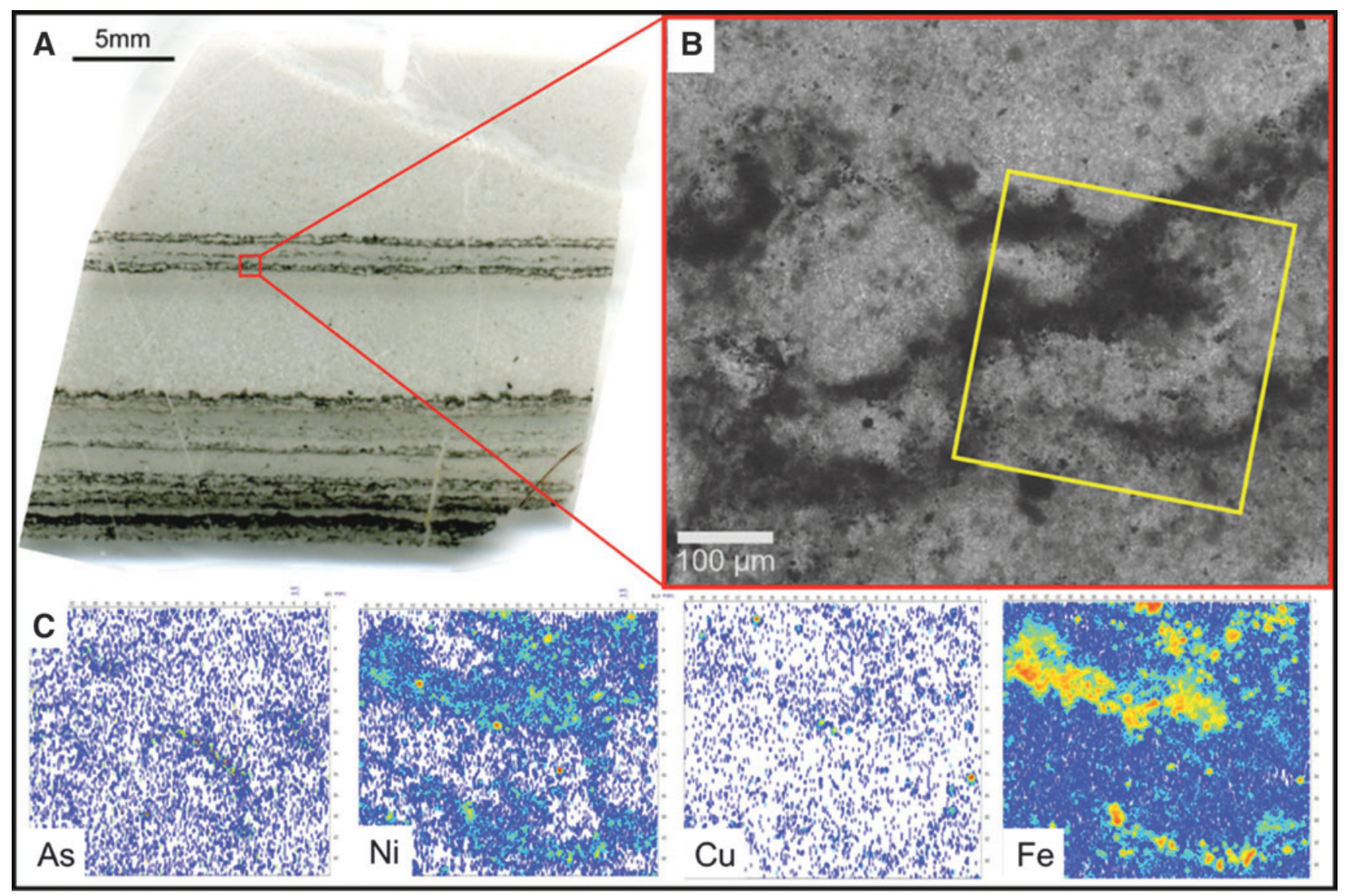

FIG. 9. Hydrothermal element scavenging by altered volcanic particles. (A) Thin section of sedimented volcanogenic particles showing dark layers comprising concentrations of volcanic particles (including spherules), as well as traces of carbon and microcrystalline pyrite (Facies D, after Westall et al., 2015a). (B) Optical micrograph of the volcanic particles in a black layer in the JC sediments. Yellow box denotes the area of the regions in (C). (C) PIXE elemental maps (beam size: $2 \mu \mathrm{m}$; map size: $300 \times 300 \mu \mathrm{m}$; resolution: $256 \times 256$ pixels; $3.5 \mathrm{~h}$ acquisition) showing the concentration of $\mathrm{Fe}, \mathrm{As}, \mathrm{Ni}$, and $\mathrm{Cu}$, trace elements of hydrothermal genesis scavenged by the altered volcanic particles.

deposits on timescales related to both silica saturation in the pore fluids and $\mathrm{pH}$. Further, as shown above, $\mathrm{pH}$ values in the sediment pore spaces of volcanic particles that are intermixed with slightly acidic seawater will initially rapidly increase (Fig. 4A). The increase in $\mathrm{pH}$ corresponds to alteration and devitrification of the volcanic particles, thus adding to silica saturation of the pore fluids. The decrease in $\mathrm{pH}$ would have influenced precipitation of the silica as silica gel. Such a mineral phase in direct contact with the reactive mineral surfaces of volcanic particles would have reduced water activity in the pore spaces, thus protecting organic molecules from hydrolysis, while at the same time limiting the range of potential chemical reactions of the organic molecules. Indeed, gels could be considered as an example of inorganic cells, protecting organic molecules, while allowing energy dissipation and molecular mobility.

3.1.2. Mixing. We have documented mixing of hydrothermal fluids (with varying amounts of admixed seawater) with the reactive volcanic sediments, the latter characterized by particle surfaces exhibiting microscale morphological variability accompanied by microscale mineralogical vari- ability and associated elemental distribution (Figs. 3-4). The mixing of carbon with the sediments and the hydrothermal fluids is important within the context of silica gels. As noted above, carbon in the JC sediments is of biogenic and abiogenic origin, but for this discussion its origin is not relevant, since its usefulness is (i) to show the presence of carbon in ancient sediments (in the prebiotic world, the carbon would have been of purely abiotic origin) and (ii) to document mixing of carbonaceous sediment with, and by, hydrothermal fluid as documented in Figs. 2 and 6.

\subsection{Physicochemical characteristics of a hydrothermal sedimentary environment}

Table 5 summarizes the characteristics of the kind of hydrothermal sedimentary environment epitomized by JC sediments. Temperatures within the sediments deposited at the interface between hot lavas and seawater, and intruded and permeated by hydrothermal fluids, would have been warm to hot. Various studies to quantify temperatures of Early Archean cherts show temperatures ranging from low, $\sim 30^{\circ} \mathrm{C}$ (Hren et al., 2009), to relatively high, $\sim 60^{\circ} \mathrm{C}$ (Tartèse et al., 2017). van den Boorn et al. (2007, 2010) 


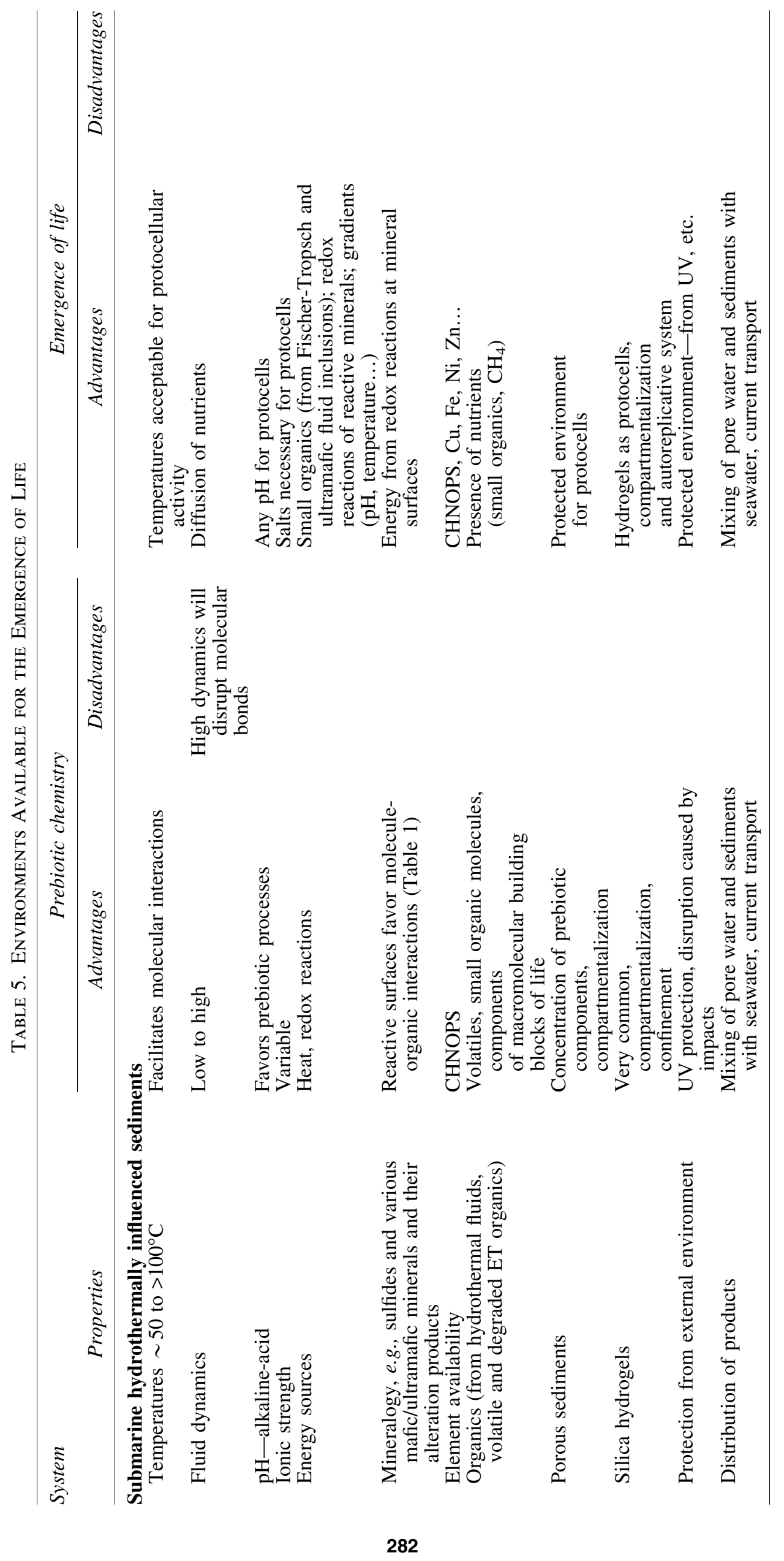


showed that temperature ranges in a similar sequence of sediments (Kitty's Gap Chert in the Pilbara; $c f$. Westall et al., 2006b) reflected fluctuating input of hydrothermal fluids and admixture with seawater. Values of $\mathrm{pH}$ would have varied from alkaline to acidic, depending upon input of hydrothermal fluids mixing with seawater and changing $\mathrm{pH}$ in pore waters during alteration of the volcanic particles. We have seen that the fluid dynamical situation in the sediment was variable, ranging from very quiescent conditions in which hydrothermal fluids simply permeated the sediments to continued forceful and disruptive intrusions that mixed all components together on longer timescales. The ionic strength of the fluids in these sediments would have been high, with a plenitude of ions being sourced from seawater, hydrothermal fluids, and the altered volcanic particles. Energy sources would have been provided from heat from the hydrothermal vents and fluids, as well as by ubiquitous, exothermic redox reactions occurring during aqueous alteration of the surfaces of the volcanic particles, the mineralogy of which consisted predominantly of volcanic glass, pyroxene, plagioclase, olivine, and their alteration minerals, together with phyllosilicates and anatase (tourmaline occurs elsewhere in similar Onverwacht Group sediments). Secondary minerals included Fe carbonate, pyrite, and barite. A meteoritic/micrometeoritic component also would be expected ( $c f$. Lowe et al., 2003; Maurette and Brack, 2006), bearing a wide range of minerals depending upon their composition (stony, iron, carbonaceous chondrite, etc.), including common pyroxene, olivine, feldspar, Fe-Ni alloys, oxides (chromite, ilmenite), and many rarer secondary species including the P-bearing mineral schreibersite (Rubin, 1997). Organic components were imported via hydrothermal fluids ( $c f$. Fig. 7B) and probably also in the carbonaceous chondritic portion of the meteoritic input. Sediment porosity varied depending on grain size and depositional processes, but permeability was assured even in the finer-grained sediments, as testified by the formation of hydrothermal siderite particles within these sediments. Deposited in water depths ranging from wave base to shore face (beach), the sediments offered some to little protection from UV radiation, depending upon water depth and depth below the sediment surface, in the case of shallow-water sediments (UV attenuation depth in different sediment types ranges from 4 to $21 \mathrm{~mm}$; Garcia-Pichel and Bebout, 1996).

An added advantage of the kind of 3-D environment envisaged in the sediment/silica gel/hydrothermal fluid mixture is the continual access to essential ingredients for prebiotic synthesis, a situation that does not exist in a 2-D environment, for instance.

Table 2 summarizes the physicochemical characteristics of environments that would favor prebiotic reactions. The characteristics of the hydrothermal volcanic sediments described here compare well with the conditions favorable for prebiotic reactions.

\subsection{Relevance of Paleoarchean sediments for the Hadean prebiotic environment}

How relevant would the Paleoarchean sediments of the JC be for a Hadean origin-of-life scenario? Would such a hydrothermal volcanic sedimentary environment have existed in the Hadean? Despite the lack of Hadean rock record, there is some remnant geochemical record from buried Hadean cratons; moreover, we have knowledge of the nature of the Paleoarchean crust. Thus, given this information and our understanding of planetary evolution, it is legitimate to envisage, at the local scale, the formation of thin layers of volcanic sediments on basaltic crust at various water depths, but especially on submerged continental crust and rare exposed land areas. Heat flow from the crust would have ensured vigorous hydrothermal circulation. At this scale and from this point of view, the JC sediments can be considered as relevant analogues for Hadean sediments and thus a suitable environment for prebiotic processes leading to the emergence of life. Prebiotic reactions could have taken place in hydrothermally influenced volcanic sediments wherever such environments occurred on the Hadean Earth and may, indeed, have been widespread.

\subsection{Comparison of hydrothermal volcanic sediments with other origin-of-life scenarios}

In any assessment of a putative geological setting for the origin of life, the environment in question must meet the three critical criteria of origination, complexification, and plausibility. These three parameters are defined as follows:

- Origination-the ability of the environment to provide the molecular and mineral components that co-facilitate prebiotic reactions;

- Complexification-the ability of the environment to sustain conditions conducive to both continued directional reactions and the overall diversification of the molecular complement of the system;

- Plausibility - the relevance of the environment to, and supposed survival on, the Hadean Earth, based upon available geological evidence.

The multifaceted aspects that comprise these criteria for each environment described above (Tables 3a-3d for hydrothermal vents, pumice rafts, subaerial geysers/nuclear hot spots, and volcanic-hosted coastal splash pools; Table 5 for hydrothermal volcanic sediments) are examined in Fig. 10. This modified "Traffic Light" diagram separates each criterion into five color-coded enumerations: green (entirely meets the criterion), yellow (generally meets the criterion with minor caveats), orange (may or may not meet the criterion due to major caveats), red (wholly fails to meet the criterion), and black (unknown or unconstrained).

We consider that any environment that has two "red lights" in the plausibility columns should be considered no further, since its existence is either implausible based on the geological record or evidentially unsupported by the ancient geological record. Five of the six environments are thus judged plausible, although subaerial hot springs (and indeed the continents upon which they would have been situated; $c f$. Kamber, 2015) were likely minor and barely pass this first test. Additionally, more than one "red light" in the origination columns is deemed a major setback in the ability of this system to facilitate prebiotic chemistry. Therefore, for pumice clasts and volcanic-hosted splash pools, their inability to generate their own organic complement makes necessary their interaction with another environment. Consequently, while these environments have numerous strengths in the 


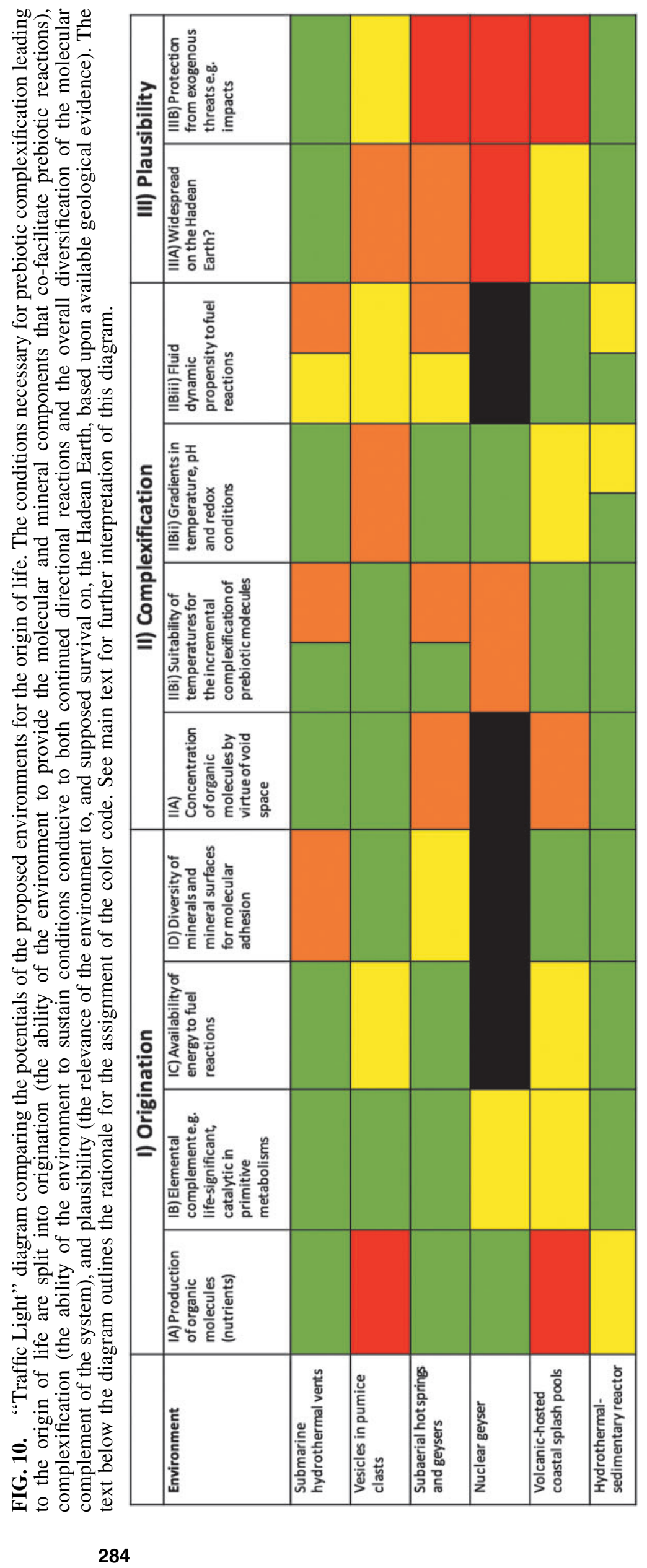



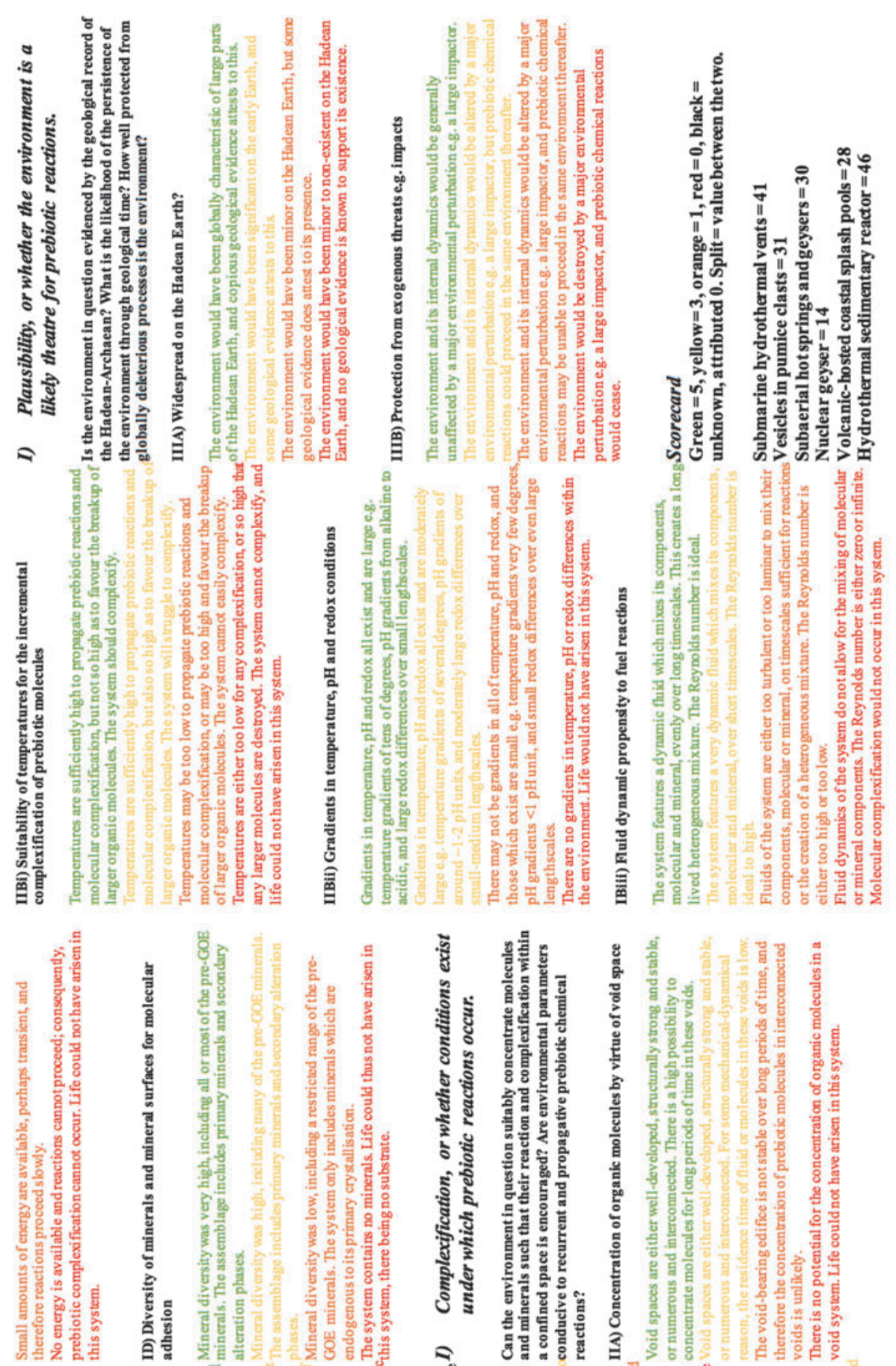

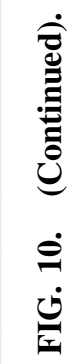
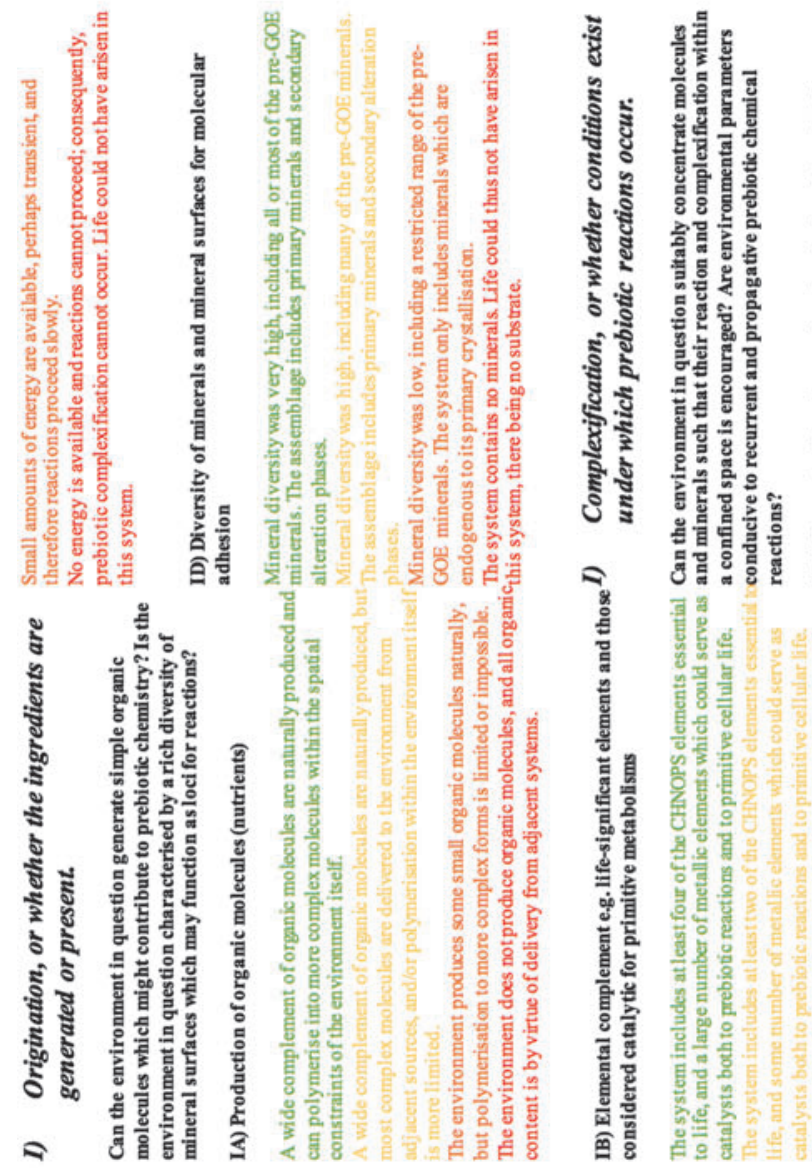

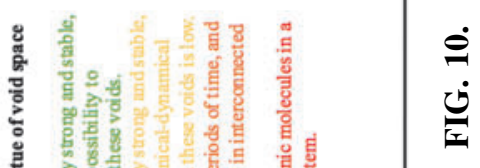

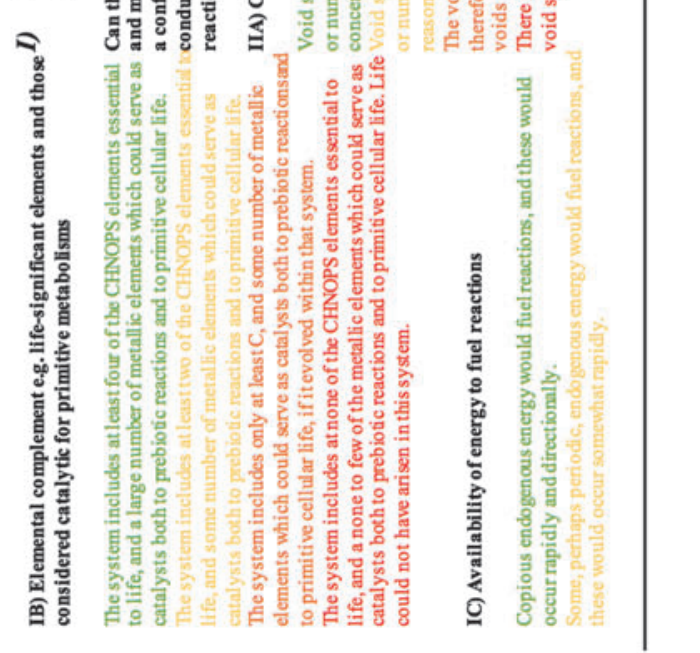


complexification stage, their effectiveness in the origination stage is poor.

The ideal setting for the origins of life would have strengths in origination and complexification, that is, its potential for prebiotic chemistry, while having no weaknesses in plausibility. The terrestrial nuclear geyser hypothesis is clearly implausible, while subaerial hot spring systems were definitely minor and short-lived. Volcanichosted terrestrial splash pools and pumice clasts suffer from an inability to generate their own prebiotic complement and are susceptible to disruption by catastrophic geological events. Only two environments pass the criteria set with mostly "green lights": submarine hydrothermal systems and the hydrothermal-sedimentary reactor. Of the two, based on our observations described from Hadean analog sediments herein, the hydrothermalsedimentary reactor has two key advantages in complexification that make it a superior setting for prebiotic chemistry:

- The more clement temperatures in this "distal" hydrothermal system are more conducive to directional prebiotic chemistry complexification reactions without the destruction of longer polymers.

- The fluid dynamics of the system is variable, leading to both mixing and quiescent conditions. This would result in higher probabilities of multiple reactions over a longer timescale and, broadly, allow more time for the totality of prebiotic complexification to occur.

A further advantage of the hydrothermal volcanic sediment scenario is the ubiquitous presence of silica gels, the advantages of which for prebiotic chemistry have been enumerated above. However, although never addressed in relation to the other environments evoked for the origin of life, silica gel could also be associated with hydrothermal vents themselves during the waning stages of their activity and also with subaerial geysers, precipitating during evaporation. Moreover, silica-saturated seawater could have precipitated in coastal splash pools also during evaporation. Finally, the porous nature of pumice rafts and their specific location at the air/water interface suggest that silica gel might have been precipitated during evaporation. Thus, to differing degrees, all the proposed environments could have had the additional advantage of silica gels.

Alkaline submarine hydrothermal vents were certainly an important part of the most plausible geological setting for the origins of life on Earth (Russell and Hall, 1997; Martin and Russell, 2003; Russell, 2007; though, for an alternative viewpoint, see Jackson, 2016). Here, we invoke aspects of this system in a more mineralogically diverse setting, that is, within hydrothermal volcanic sediments, and with more moderate dynamic conditions, as an alternative and likely ubiquitous setting for prebiotic molecular complexification leading to the appearance of life.

\section{Summary and Conclusions}

Our observations on Paleoarchean sediments judged analogous to those in similar Hadean environments document an environment consisting of reactive volcanogenic sediments deposited at the interface between volcanic lithosphere and the hydrosphere, a seawater-sediment interface strongly influenced by hydrothermal fluids and rapid alteration of mafic-ultramafic minerals, and therefore characterized by temperature and $\mathrm{pH}$ disequilibria (Westall et al., 2015b; Westall, 2016; Fig. 11). Alkaline and highly reduced $\left(\mathrm{H}_{2}\right.$-rich) hydrothermal fluid effluent, as well as alkaline fluids resulting from the alteration of volcanic grains, would have intermixed with the relatively more acidic $\left(\mathrm{CO}_{2}\right.$-rich $)$ ocean water, creating a gradient in redox conditions (Martin et al., 2008) within the sediments and at the sediment-water interface. Temperature disequilibria would have resulted from the variable pulsing of hydrothermal fluids within the sediments and mechanical mixing with the overlying seawater. The natural heterogeneity of the sedimentary materials described here (mineralogy, chemistry, porous texture, particle morphology, pore-fluid $\mathrm{pH}$, and temperature) provided for a plurality of surface-solution interactions akin to a contiguous, flow-through chemical reactor. The sediments, together with silica gel, would create a network of pore spaces, each with a local microenvironment conducive to producing a range of prebiotic organic molecules. Within the pores, interaction of water with the functional groups (silanol) of the silica gel and mineral grains would have limited the ability of water molecules to hydrolyze the organic molecules attached to the minerals, thus facilitating the formation of building blocks of peptides and nucleotides, for example. These gels, associated with minerals in the sediments, could have acted as a diffusional barrier to achieve the required retention time for complex chemistry to emerge (cf. Trevors and Pollack, 2005). In this setting, heat-driven convection would have been fundamental for transporting reactants to multiple reaction sites (Simoncini et al., 2011). The hydrothermal pathways through sedimentary systems could have distributed soluble compounds leading to their distal accumulation.

From the perspective of prebiotic chemistry, sedimentary systems on the primitive Earth offered possibilities for the processing of raw organic matter provided by serpentinizing systems, liberated from ultramafic fluid inclusions, and delivered by meteoritic infall. While serpentinizing systems are highly attractive as a source of both the reducing potential and carbon required to build a molecular inventory (Baross and Hoffman, 1985; Russell and Hall, 1997; Martin et al., 2008; Sleep et al., 2011; though see McCollom and Donaldson, 2016, for an alternate view), to date little attention has been given to the chemical modification of extraterrestrial carbon in early hydrothermal-based theories for life's origins (Baross and Hoffman, 1985; Russell and Hall, 1997; Martin and Russell, 2007; Martin et al., 2008; Simoncini et al., 2011). As noted above, meteorite and micrometeorite analyses strongly support early, massive, and widespread delivery of extraterrestrial organics, corresponding to as much as $10 \%$ of the oxidized carbon remaining in the modern biomass (Sephton, 2002) and additionally providing minerals containing potentially reactive metals (Maurette, 2006; Pizzarello and Shock, 2010). About 75\% of the carbonaceous matter distributed within carbonaceous chondrites is insoluble macromolecular material (Pizzarello and Shock, 2010), which would have concentrated in the sediments. Subsequently, reaction with hot fluids would have contributed to the breakdown of recalcitrant organic matter and its subsequent availability for prebiotic chemistry on reactive mineral surfaces within the sediments. 


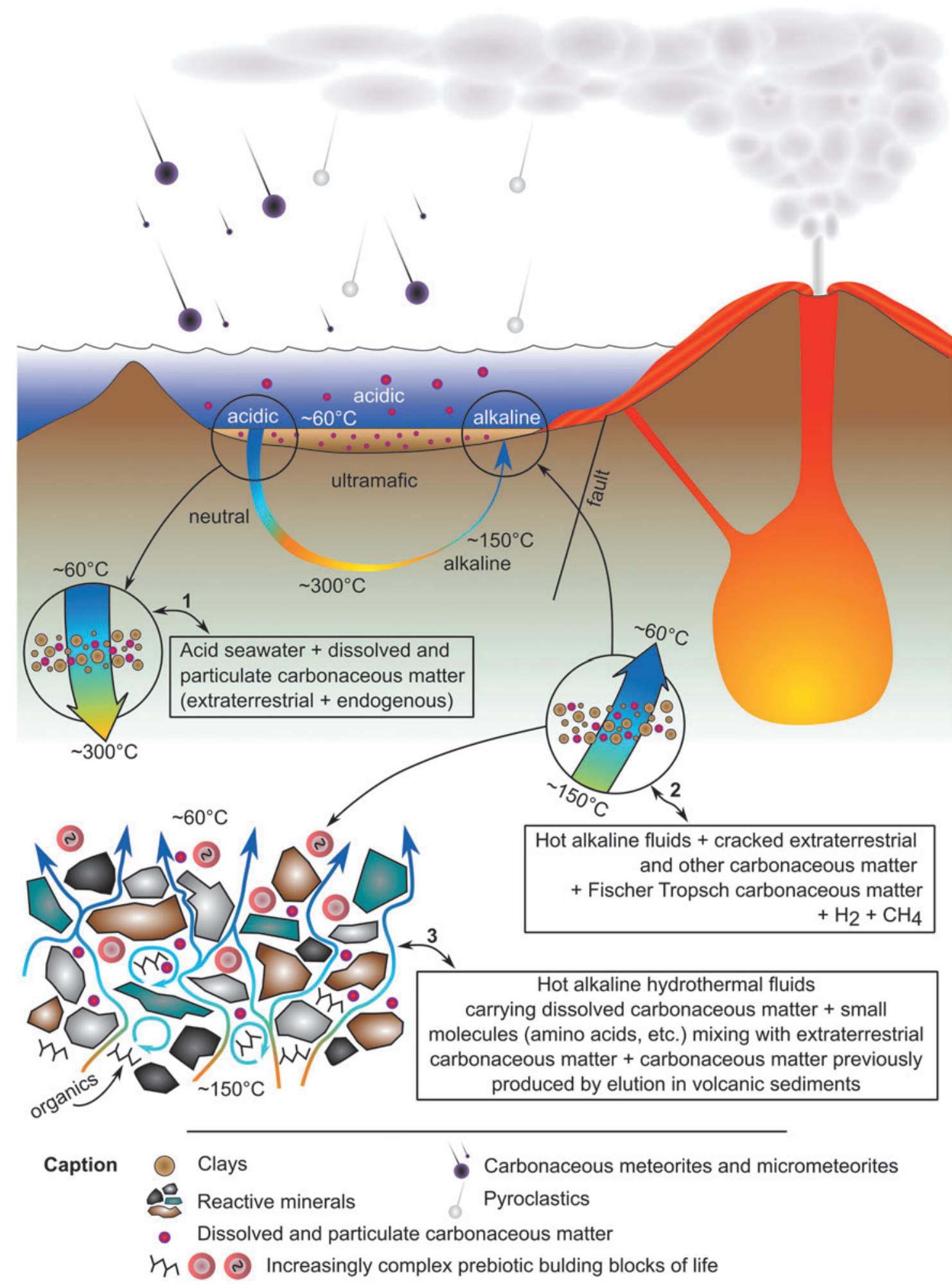

FIG. 11. Schematic synthesis of the proposed Hadean, hydrothermal-sedimentary micro-reactor environment for complexification of prebiotic chemistry. Slightly acidic seawater entraining dissolved and particulate carbonaceous matter of diverse origins permeates through ultramafic/mafic sediments into the crust (insert 1), altering the ultramafic rocks and becoming more alkaline during these reactions. Light-weight carbon molecules and gases (e.g., $\left.\mathrm{H}_{2}, \mathrm{CH}_{4}\right)$ formed by Fischer-Tropsch-type processes (Shock et al., 2002), as well as molecules from ultramafic fluid inclusions (Van Kranendonk et al., 2015), were convected into reactive porous sediments at the bottom of the sea (the sediment-water interface, insert 2), where a temperature and $\mathrm{pH}$ disequilibrium (insert 3) with the overlying acidic seawater existed. Convection of warm, carbon-bearing hydrothermal fluids allowed prebiotic molecules to concentrate and self-assemble in pore spaces and on the surfaces of chemically reactive minerals, resulting in the formation of increasingly complex molecules. 
Thus, porous, reactive sediments on a hydrothermally active Hadean Earth provided a UV-protected environment at a critical chemical, thermal, and dynamical disequilibrium interface (Table 1) and could have hosted globally distributed, miniature chemical reactors in the form of sedimentary pore space, as summarized in Fig. 11.

\section{Appendix A. Materials and Methods}

Our study is based on extensive field and microscopic examination of silicified volcanic sediments ranging from 3.46 to 3.33 billion years in age, from the Barberton Greenstone Belt in South Africa and the Pilbara in Australia. More specifically for this investigation, we have made a detailed, complementary microscopic, mineralogical, and geochemical study of a suite of samples from the JC (3.33 Ga, Westall et al., 2015a) in the Barberton Greenstone Belt (Fig. 1). Samples were collected during field campaigns between 1999 and 2014.

Optical microscopy was conducted on 30-60 $\mu \mathrm{m}$ polished thin sections using an Olympus BX51 microscope at CNRSCBM (Orléans). Scanning electron microscopy, in backscatter mode, of the surfaces of uncoated, polished thin sections was conducted at CNRS-ISTO (Orléans), with a Hitachi TM3000 Tabletop SEM equipped with a Swift ED3000 silicon drift detector operating at $15 \mathrm{kV}$. Elemental maps were acquired with a resolution of $512 \times 384$ pixels for 60 min using a line length of $75.4 \mu \mathrm{m}$ (magnification $\times 1500$ ). Raman analyses were undertaken at CNRS-CBM (Orléans) on polished thin sections using a WITec Alpha500 RA Raman spectrometer following the method described in Westall et al. (2015a). Whole rock analyses were conducted utilizing laser ablation ICP-MS and ICP-OES at the University of Cardiff. The REE concentrations were normalized to PAAS shale (McLennan, 1989). In situ elemental mapping was undertaken on $60-80 \mu \mathrm{m}$ thick rock sections by PIXE at the AIFIRA facility (Applications Interdisciplinaires des Faiseaux d'Ions en Région Aquitaine), CENBG (Bordeaux-Gradignan). Acquisitions were made with $3 \mathrm{MeV}$ proton microbeam $(1 \mu \mathrm{m}$ diameter) using two $\mathrm{Si}(\mathrm{Li})$ detectors equipped with (1) $\mathrm{Al}$ $100 \mu \mathrm{m}$ thick Mylar "funny" filter with a $2 \mathrm{~mm}$ hole and a $50 \mu \mathrm{m}$ thick kapton filter used to eliminate the Si signal; (2) $100 \mu \mathrm{m}$ thick Al "funny" filter with a $1 \mathrm{~mm}$ hole. Beam intensity is kept low enough to have less than $10 \%$ dead time on detectors.

The composition of Hadean seawater (Table 4) was calculated by PHREEQC (Parkhurst and Appelo, 1999) with the 1lnl (Lawrence Livermore National Laboratory) thermodynamic database (Johnson et al., 2000; Blasco et al., 2017). The initial suite of ultramafic/mafic minerals represented the komatiites and basalts present during the Hadean (Arndt, 1994; Hazen et al., 2008). These minerals were fosterite, bytownite, diopside, and ilmenite (Table 2). Two models were tested: (i) an initial solution of hot (50$\left.100^{\circ} \mathrm{C}\right), \mathrm{CO}_{2}$-rich $\left(\mathrm{PCO}_{2} 1-10 \mathrm{~atm}\right)$ solution, equilibrated with the mineral suite by dissolution only without additional gas equilibration, representing advection of acidic seawater through the igneous rocks without additional equilibration with the atmosphere; and (ii) simultaneous equilibration of the minerals with atmospheric $\mathrm{PCO}_{2}$, representing continuous connection of hydrothermal fluids with acidic seawater (Table 3).

\section{Acknowledgments}

We thank William F. Martin (Düsseldorf) for fruitful discussion on the origin and emergence of life in the geological context of hydrothermal systems. We thank Fabio Sgargi for editorial help. Funding was provided by the French Space Agency (CNES), ANR-09-BLAN-0219-01, and CNRS-MI-2014 awards to F.W., from the Marsden Fund (RSNZ) to K.C., and from a LE STUDIUM ${ }^{\circledR}$ research fellowship to K.C. We thank Norm Sleep and four anonymous reviewers who provided critical reviews which contributed greatly to the refinement of the manuscript.

\section{References}

Akouche, M., Jaber, M., Zins, E.-L., Maurel, M.C., Lambert, J.F., and Georgelin, T. (2016) Thermal behavior of D-ribose absorbed on silica: effect of inorganic salt coadsorption and significance for prebiotic chemistry. Chemistry 22:1-14.

Arndt, N.T. (1994) Archean komatiites. In Archean Crustal Evolution, edited by K.C. Condie, Elsevier, Amsterdam, pp 11-44.

Bailey, J. (2001) Astronomical sources of circularly polarized light and the origin of homochirality. Orig Life Evol Biosph 31:167-183.

Baross, J.A. and Hoffman, S.E. (1985) Submarine hydrothermal vents and associated gradient environments as sites for the origin and evolution of life. Orig Life Evol Biosph 15:327-345.

Bell, E.A., Boehnke, P., Harrison, T.M., and Maob, W.L. (2015) Potentially biogenic carbon preserved in a 4.1 billionyear-old zircon. Proc Natl Acad Sci USA 112:14518-14521.

Benner, S.R., Ricardo, A., Illangkoon, H., Kim, M.J., Carrigan, M., Frye, F., and Benner, D.S. (2008) Elements and the origin of life. Boron and molybdenum [abstract B24C-01]. In AGU 2008 Fall Meeting, American Geophysical Union, Washington, DC.

Bertrand, M. and Brack, A. (2000) Conformational transition of acidic peptides exposed to minerals in suspension Chemistry 6:3452-3455.

Bickle, M.J., Nisbet, E.G., and Martin, A. (1994) Archean greenstone belts are not oceanic crust. J Geol 102:121-138.

Blake, R.E., Chang, S.J., and Lepland, A. (2010) Phosphate oxygen isotope evidence for a temperate and biologically active Archean ocean. Nature 464:1029-1033.

Blasco, M., Gimeno, M.J., and Auqué, L.F. (2017) Comparison of different thermodynamic databases used in a geothermometrical modeling calculation. Procedia Earth and Planetary Science 17:120-123.

Bleeker, W. (2004) Towards a 'natural' time scale for the Precambrian-a proposal. Lethaia 37:219-222.

Bonner, W.A. (1991) The origin and amplification of biomolecular chirality. Orig Life Evol Biosph 21:59-111.

Bottke, W.F., Vokrouhlicky, D., Minton, D., Nesvorny, D., Morbidelli, A., Brasser, R., Simonson, B., and Levison, H.F. (2012) An Archaean heavy bombardment from a destabilized extension of the asteroid belt. Nature 485:78-81.

Brack, A. and Orgel, L. (1975) $\beta$ structures of alternating polypeptides and their possible prebiotic significance. Nature 256:383-387.

Brandes, J.A., Boctor, N.Z., Cody, G.D., Cooper, B.A., Hazen, R.M., and Yodor, H.S. (1998) Abiotic nitrogen reduction on the early Earth. Nature 395:365-367.

Brasier, M.D., Matthewman, R., McMahon, S., and Wacey, D. (2011) Pumice as a remarkable substrate for the origin of life. Astrobiology 11:725-735. 
Brasier, M.D., Matthewman, R., McMahon, S., Kilburn, M.R., and Wacey, D. (2013) Pumice from the $\sim 3460$ Ma Apex Basalt, Western Australia: a natural laboratory for the early biosphere. Precambrian Res 224:1-10.

Braunstein, D. and Lowe, D.R. (2001) Relationship between spring and geyser activity and the deposition and morphology of high temperature $\left(>73^{\circ} \mathrm{C}\right)$ siliceous sinter, Yellowstone National Park, Wyoming, U.S.A. J Sediment Res 71:747-763.

Breuer, D. and Spohn, T. (1995) Possible flush instability in mantle convection at the Archaean-Proterozoic transition. Nature 378:608-610.

Brito, A., Garcia, F., Alvarez, C., Arvelo, R., Fierro, J.L.G., and Diaz, C. (2004) High surface area support/catalyst derived from natural pumice: study of pretreatment variables. Ind Eng Chem Res 43:1659-1664.

Cady, S.L. and Farmer, J.D. (1996) Fossilization processes in siliceous thermal springs: trends in preservation along thermal gradients. In Evolution of Hydrothermal Ecosystems on Earth (and Mars?), edited by G.R. Bock and J.A. Goode, Ciba Foundation Symposium 202, John Wiley, Chichester, pp 150-173.

Campbell, K.A., Lynne, B.Y., Handley, K.M., Jordan, S., Farmer, J.D., Guido, D.M., Foucher, F., Turner, S., and Perry, R.S. (2015) Tracing biosignature preservation of geothermally silicified microbial textures into the geological record. Astrobiology 15:859-882.

Cleaves, H.J., Michalkova Scott, A., Hill, F.C., Leszczynski, J., Sahai, N., and Hazen, R.M. (2012) Mineral-organic interfacial processes: potential roles in the origin of life. Chem Soc Rev 41:5502-5525.

Cockell, C.S. and Raven, J.A. (2004) Zones of photosynthetic potential on Mars and the early Earth. Icarus 169:300-310.

Cockell, C.S., Osinsski, G.R., Banerjee, N.R., and Watson, J. (2010) The microbe-mineral environment and gypsum neogenesis in a weathered polar evaporate. Geobiology 8:293-308.

Copley, S.D., Smith, E., and Morowitz, H.J. (2007) The origin of RNA world: co-evolution of genes and metabolism. Bioorg Chem 35:430-443.

Cox, M.M. and Battista, J.R. (2005) Deinococcus radioduransthe consummate survivor. Nature Rev Microbiol 3:882-892.

Damer, B.F. and Deamer, D.W. (2015) Coupled phases and combinatorial selection in fluctuating hydrothermal pools: a scenario to guide experimental approaches to the origin of cellular life. Life 5:872-887.

Damer, B.F. and Deamer, D.W. (2017) An origin of life in terrestrial fresh water hydrothermal pools [abstract 3220]. In Astrobiology Science Conference, Lunar and Planetary Institute, Houston, LPI contribution \#1965.

Danielson, A., Möller, P., and Dulski, P. (1992) The europium anomalies in banded iron formations and the thermal history of the oceanic crust. Chem Geol 97:89-100.

Dass, A.V., Hickman-Lewis, K., Brack, A., Kee, T.P., and Westall, F. (2016) Stochastic prebiotic chemistry within realistic geological systems. ChemistrySelect 1:4906-4926.

Deamer, D.W. and Georgiou, C.D. (2015) Hydrothermal conditions and the origin of cellular life. Astrobiology 15:10911095.

Debaille, V., O’Neill, C., Brandon, A.D., Haenecour, P., Yin, Q.Z., Mattielli, N., and Treiman, A.H. (2013) Stagnant-lid tectonics in early Earth revealed by Nd-142 variations in late Archean rocks. Earth Planet Sci Lett 373:83-92.

Derry, L.A. and Jacobsen, S.B. (1999) The chemical evolution of Precambrian seawater: evidence from REEs in banded iron formations. Geochim Cosmochim Acta 54:2965-2977. de Vries, S.T., Nijman, W., and de Boer, P.L. (2010) Sedimentary geology of the Palaeoarchaean Buck Ridge (South Africa) and Kittys Gap (Western Australia) volcanosedimentary complexes. Precambrian Res 183:749-769.

de Wit, M.J. and Furnes, H. (2016) 3.5-Ga hydrothermal fields and diamictites in the Barberton Greenstone Belt-Paleoarchean crust in cold environments. Sci Adv 2, doi:10.1126/sciadv .1500368 .

Dibrova, D.V., Galperin, M.Y., Koonin, E.V., and Mulkidjanian, A.Y. (2015) Ancient systems of sodium/potassium homeostasis as predecessors of membrane bioenergetics. Biochemistry 80:590-611.

Djokic, T., Van Kranendonk, M.J., Campbell, K.A., Walter, M.R., and Ward, C.R. (2017) Earliest signs of life on land preserved in ca. $3.5 \mathrm{Ga}$ hot spring deposits. Nat Commun 8, doi:10.1038/ncomms15263.

dos Santos, R., Patel, M., Cuadros, J., and Martins, Z. (2016) Influence of mineralogy on the preservation of amino acids under simulated Mars conditions. Icarus 277:342-353.

Ebisuzaki, T. and Maruyama, S. (2017) Nuclear geyser model of the origin of life: driving force to promote the synthesis of building blocks of life. Geoscience Frontiers 8:275-298.

Fox, S. and Strasdeit, H. (2013) A possible prebiotic origin on volcanic islands of oligopyrrole-type photopigments and electron transfer cofactors. Astrobiology 13:578-595.

Friend, C.R.L., Nutman, A.P., Bennett, V.C., and Norman, M.D. (2008) Seawater-like trace element signatures (REE+Y) of Eoarchaean chemical sedimentary rocks from southern West Greenland, and their corruption during high-grade metamorphism. Contrib Mineral Petrol 155:229-246.

Garcia-Pichel, F. and Bebout, B.M. (1996) Penetration of ultraviolet radiation into shallow water sediments: high exposure for photosynthetic communities. Mar Ecol Prog Ser 131: 257-262.

Georgelin, T., Jaber, M., Bazzi, H., and Lambert, J.F. (2013) Formation of activated biomolecules by condensation on mineral surfaces - a comparison of peptide bond formation and phosphate condensation. Orig Life Evol Biosph 43:429-443.

Goldblatt, C., Lenton, T.M., and Watson, A.J. (2006) Bistability of atmospheric oxygen and the Great Oxidation. Nature 443: 683-686.

Grew, E.S., Bada, J.L., and Hazen, R.M. (2011) Borate minerals and origin of the RNA world. Orig Life Evol Biosph 41:307-316.

Griffin, W.L., Belousova, E.A., O’Neill, C., O'Reilly, S.Y., Malkovets, V., Pearson, N.J., Spetsius, S., and Wilde, S.A. (2014) The world turns over: Hadean-Archean crust-mantle evolution. Lithos 189:2-15.

Grosch, E.G. and Hazen, R.M. (2015) Microbes, mineral evolution, and the rise of micro-continents: origin and coevolution of life with early Earth. Astrobiology 15:922-939.

Grotzinger, J.P. and Kasting, J.F. (1993) New constraints on Precambrian ocean composition. J Geol 101:235-243.

Gull, M., Mojica, M.A., Fernandez, F.M., Gaul, D.A., Orlando, T.M., Liotta, C.L., and Pasek, M.A. (2015) Nucleoside phosphorylation by the mineral schreibersite. Sci Rep 5: 17198

Haqq-Misra, J., Domagal-Goldman, S.D., Kasting, P.J., and Kasting, J.F. (2008) A revised, hazy methane greenhouse for the Archaean Earth. Astrobiology 8:1127-1137.

Hazen, R.M. (2001) Life's rocky start. Sci Am 284:76-85.

Hazen, R.M. (2004) Chiral crystal faces of common rockforming minerals. In Progress in Biological Chirality, edited by G. Palyi, C. Zucchi, and L. Cagglioti, Elsevier, New York, pp 137-151. 
Hazen, R.M. and Sverjensky, D.A. (2010) Mineral surfaces, geochemical complexities, and the origins of life. Cold Spring Harb Perspect Biol 2, doi:10.1101/cshperspect .a002162.

Hazen, R.M., Papineau, D., Bleeker, W., Downs, R.T., Ferry, J., McCoy, T., Sverjensky, D., and Yang, H. (2008) Mineral evolution. Am Mineral 93:1693-1720.

Hessler, A.M., Lowe, D.R., Jones, R.L., and Bird, D.K. (2004) A lower limit for atmospheric carbon dioxide levels 3.2 billion years ago. Nature 428:736-738.

Heubeck, C. and Lowe, D.R. (1994) Depositional and tectonic setting of the Archean Moodies Group, Barberton greenstonebelt, South-Africa. Precambrian Res 68:257-290.

Hinman, N.W. and Walter, M.R. (2005) Textural preservation in siliceous hot spring deposits during early diagenesis: examples from Yellowstone National Park and Nevada, U.S.A. J Sediment Res 75:200-215.

Holm, N.G. and Charlou, J.L. (2001) Initial indications of abiotic formation of hydrocarbons in the Rainbow ultramafic hydrothermal system, Mid-Atlantic Ridge. Earth Planet Sci Lett 191:1-8.

Hopkins, M.D., Harrison, T.M., and Manning, C.E. (2010) Constraints on Hadean geodynamics from mineral inclusions in >4 Ga zircons. Earth Planet Sci Lett 298:367-376.

Hren, M.T., Tice, M.M., and Chamberlain, C.P. (2009) Oxygen and hydrogen isotope evidence for a temperate climate 3.42 billion years ago. Nature 205:205-208.

Hubert, A. (2015) Chemical and mineralogical signatures of oxygenic photosynthesis in Archean and Paleoproterozoic sediments. $\mathrm{PhD}$ thesis, University of Orléans, Orléans, France.

Islam, S. and Powner, M.W. (2017) Prebiotic systems chemistry: complexity overcoming clutter. Chem 2:470-501.

Jackson, J.B. (2016) Natural pH gradients in hydrothermal alkali vents were unlikely to have played a role in the origin of life. J Mol Evol 83:1-11.

Johnson, J., Anderson, F., and Parkhurst, D.L. (2000) Database thermo.com. V8.R6.230, Rev 1.11. Lawrence Livermore National Laboratory, Livermore, CA.

Johnson, T.E., Brown, M., Kaus, B.J.P., and VanTongeren, J.A. (2014) Delamination and re-cycling of Archaean crust caused by gravitational instabilities. Nat Geosci 7:47-52.

Jones, B. and Renaut, R.W. (2003) Petrography and genesis of spicular and columnar geyserites from the Whakarewarewa and Orakeikorako geothermal areas, North Island, New Zealand. Can J Earth Sci 40:1585-1610.

Jones, B., Renaut, R.W., and Rosen, M.R. (2001) Taphonomy of silicified filamentous microbes-implications for identification. Palaios 16:580-592.

Jonsson, C.M., Jonsson, C.L., Sverjensky, D.A., Cleaves, H.J., and Hazen, R.M. (2009) Attachment of L-glutamate to rutile $\left(\alpha-\mathrm{TiO}_{2}\right)$ : a potentiometric, adsorption, and surface complexation study. Langmiur 25:12127-12135.

Kamber, B.S. (2015) The evolving nature of terrestrial crust from the Hadean, through the Archaean, into the Proterozoic. Precambrian Res 258:48-82.

Kamber, B.S., Collerson, K.D., Moorbath, S., and Whitehouse, M.J. (2003) Inheritance of early Archaean Pb-isotope variability from long-lived Hadean protocrust. Contrib Mineral Petrol 145:25-46.

Kashefi, K. and Lovley, D.R. (2003) Extending the upper temperature limit for life. Science 301:934.

Kasting, J.F. (1993) Earth's early atmosphere. Science 259: 920-926.
Kelley, D.S., Karson, J.A., Blackman, D.K., Fruh-Green, G.L., Butterfield, D.A., Lilley, M.D., Olson, E.J., Schrenk, M.O., Roe, K.K., Lebon, G.T., Rivizzigno, P., and the A.T.S.P. (2001) An off-axis hydrothermal vent field near the MidAtlantic Ridge at $30^{\circ}$ N. Nature 412:145-149.

Kemp, A.I.S., Wilde, S.A., Hawkesworth, C.J., Coath, C.D., Nemchin, A., Pidgeon, R.T., Vervoort, J.D., and DuFrane, S.A. (2010) Hadean crustal evolution revisited: new constraints from $\mathrm{Pb}-\mathrm{Hf}$ isotope systematics of the Jack Hills zircons. Earth Planet Sci Lett 296:45-56.

Kempe, S. and Degens, E.T. (1985) An early soda ocean? Chem Geol 53:95-108.

Koeberl, C. (2006) The record of impact processes on the early Earth-a review of the first 2.5 billion years. In Processes of the Early Earth, Geological Society of America Special Paper 405, edited by W.U. Reimold and R.L. Gibson, Geological Society of America, Boulder, CO, pp 1-22.

Konhauser, K.O. and Ferris, F.G. (1996) Diversity of iron and silica precipitation by microbial mats in hydrothermal waters, Iceland: Implications for Precambrian iron formations. Geology 24:323-326.

Korenaga, J. (2013) Initiation and evolution of plate tectonics on Earth: theories and observations. Annu Rev Earth Planet Sci 41:117-151.

Kramers, J.D. (2003) Volatile element abundance patterns and an early liquid water ocean on Earth. Precambrian Res 126: 379-394.

Lambert, J.B., Gurusamy-Thangavelu, S.A., and Ma, K. (2010) The silicate-mediated formose reaction: bottom-up synthesis of sugar silicates. Science 327:984-986.

Lanier, W.P. and Lowe, D.R. (1982) Sedimentology of the Middle Marker (3.4Ga), Onverwacht Group, Transvaal, South Africa. Precambrian Res 18:237-260.

Ledevin, M., Arndt, N., Simionovici, A., Jaillard, E., and Ulrich, M. (2014) Silica precipitation triggered by clastic sedimentation in the Archean: new petrographic evidence from cherts of the Kromberg type section, South Africa. Precambrian Res 255:316-334.

Livo, K.E., Kruse, F.A., Clark, R.N., Kokaly, R.F., and Shanks, W.C., III. (2007) Hydrothermally altered rock and hot spring deposits at Yellowstone National Park-characterized using airborne visible- and infrared-spectroscopy data. In Integrated Geoscience Studies of the Greater Yellowstone Area-Volcanic, Tectonic, and Hydrothermal Processes in the Yellowstone Ecosystem, edited by L.A. Morgan, USGS Professional Paper 1717, US Geological Survey, Reston, VA.

Lowe, D.R. and Byerly, G.R. (1999) Stratigraphy of the westcentral part of the Barberton Greenstone Belt, South Africa. In Geologic Evolution of the Barberton Greenstone Belt, South Africa, Geological Society of America Special Paper 329, edited by D.R. Lowe and G.R. Byerly, Geological Society of America, Boulder, CO, pp 1-36.

Lowe, D.R. and Fisher Worrell, G. (1999) Sedimentology, mineralogy, and implications of silicified evaporites in the Kromberg Formation, Barberton Greenstone Belt, South Africa. In Geologic Evolution of the Barberton Greenstone Belt, South Africa, Geological Society of America Special Paper 329, edited by D.R. Lowe and G.R. Byerly, Geological Society of America, Boulder, CO, pp 167-188.

Lowe, D.R., Byerly, G.R., Kyte, F.T., Shukolyukov, A., Asaro, F., and Krull, A. (2003) Spherule beds 3.47-3.24 billion years old in the Barberton Greenstone Belt South Africa: a record of large meteorite impacts and their influence on early crustal and biological evolution. Astrobiology 3:7-48. 
Marchi, S., Bottke, W.F., Elkins-Tanton, L.T., Bierhaus, M., Wuennemann, K., Morbidelli, A., and Kring, D.A. (2014) Widespread mixing and burial of Earth's Hadean crust by asteroid impacts. Nature 511:578-582.

Marin-Carbonne, J., Robert, F., and Chaussidon, M. (2014) The silicon and oxygen isotope compositions of Precambrian cherts: a record of oceanic paleo-temperatures? Precambrian Res 247:223-234.

Martin, W. and Russell, M.J. (2003) On the origins of cells: a hypothesis for the evolutionary transitions from abiotic geochemistry to chemoautotrophic prokaryotes, and from prokaryotes to nucleated cells. Philos Trans R Soc Lond B Biol Sci 358:59-85.

Martin, W. and Russell, M.J. (2007) On the origin of biochemistry at an alkaline hydrothermal vent. Philos Trans $R$ Soc Lond B Biol Sci 362:1887-1925.

Martin, W.F., Baross, J., Kelley, D., and Russell, M.J. (2008) Hydrothermal vents and the origin of life. Nat Rev Microbiol 6:805-814.

Mather, T.A., Pyle, D.M., and Allen, A.G. (2004) Volcanic source for fixed nitrogen in the early Earth's atmosphere. Geology 32:905-908.

Maurette, M. (2006) Micrometeorites and the Mysteries of Our Origins, Springer, Berlin.

Maurette, M. and Brack, A. (2006) Cometary petroleum in Hadean time? Meteorit Planet Sci 41:5247.

McCollom, T.M. and Donaldson, C. (2016) Generation of hydrogen and methane during experimental low-temperature reaction of ultramafic rocks with water. Astrobiology 16:389-406.

McDermott, J.M., Seewald, J.S., German, C.R., and Sylva, S.P. (2015) Pathways for abiotic organic synthesis at submarine hydrothermal fields. Proc Natl Acad Sci USA 112:7668-7672.

McLennan, S.M. (1989) Rare earth elements in sedimentary rocks: influence of provenance and sedimentary processes. Reviews of Mineralogy 21:169-200.

Meinert, C., Myrgorodska, I., de Marcellus, P., Buhse, T., Nahon, L., Hoffmann, S.V., Le Sergeant d'Hendecourt, L., and Meierhenrich, U.J. (2016) Ribose and related sugars from ultraviolet irradiation of interstellar ice analogs. Science 352: 208-212.

Mojzsis, S.J., Harrison, T.M., and Pidgeon, R.T. (2001) Oxygenisotope evidence from ancient zircons for liquid water at the Earth's surface 4,300 Myr ago. Nature 409:178-181.

Morse, J.W. and Mackenzie, F.T. (1998) Hadean ocean carbonate geochemistry. Aquat Geochem 4:301-319.

Mulkidjanian, A.Y., Cherepanov, D.A., and Galperin, M.Y. (2003) Survival of the fittest before the beginning of life: selection of the first oligonucleotide-like polymers by UV light. BMC Evol Biol 3, doi:10.1186/1471-2148-3-12.

Mulkidjanian, A.Y., Byckkov, A.Y., Dibrova, D.V., Galperin, M.Y., and Koonin, E.V. (2012a) Origin of first cells at terrestrial, anoxic geothermal fields. Proc Natl Acad Sci USA 109:E821-E830.

Mulkidjanian, A.Y., Bychkov, A.Y., Dibrova, D.V., Galperin, M.Y., and Koonin, E.V. (2012b) Open questions on the origin of life at anoxic geothermal fields. Orig Life Evol Biosph 42: 507-516.

Negrón-Mendoza, A., Ramos-Bernal, S., Colín-Garcá, M., and Heredia, A. (2016) Chemical evolution: an approach from radiation chemistry. Radiation \& Applications 1:159-164.

Nemchin, A.A., Pidgeon, R.T., and Whitehouse, M.J. (2006) Re-evaluation of the origin and evolution of $>4.2 \mathrm{Ga}$ zircons from the Jack Hills metasedimentary rocks. Earth Planet Sci Lett 244:218-233.
Neveu, M., Kim, H.-J., and Benner, S.A. (2013) The "strong" RNA world hypothesis: fifty years old. Astrobiology 13:391-403.

Nisbet, E.G. and Sleep, N.H. (2001) The habitat and nature of early life. Nature 409:1083-1091.

Parkhurst, D.L. and Appelo, C.A.J. (1999) User's Guide to PHREEQC (version 2)-A Computer Program for Speciation, Reaction-Path, 1D-Transport, and Inverse Geochemical Calculations, USGS Water Resources Inventory Report 99-4259, US Geological Survey, Denver, CO.

Parsons, I., Lee, M.R., and Smith, J.V. (1998) Biochemical evolution II: origin of life in tubular microstructures on weathered feldspar surfaces. Proc Natl Acad Sci USA 95: 15173-15176.

Patel, B.H., Percivalle, C., Ritson, D.J., Duffy, C.D., and Sutherland, J.D. (2015) Common origins of RNA, protein and lipid precursors in a cyanosulfidic protometabolism. Nat Chem 7:301-307.

Pavlov, A.A., Kasting, J.F., Brown, L.L., Rages, K.A., and Freedman, R. (2000) Greenhouse warming by $\mathrm{CH}_{4}$ in the atmosphere of early Earth. J Geophys Res 105:11981-11990.

Pizzarello, S. and Shock, E. (2010) The organic composition of carbonaceous meteorites: the evolutionary story ahead of biochemistry. Cold Spring Harb Perspect Biol 2, doi:10.1101/ cshperspect.a002105.

Pollack, G.H. (2001) Cells, Gels and the Engines of Life, Ebner and Sons, Seattle WA.

Reid, C. and Orgel, L.E. (1967) Model for origin of monosaccharides: synthesis of sugars in potentially prebiotic conditions. Nature 216, doi:10.1038/216455a0.

Ricardo, A., Carrigan, M.A., Olcott, A.N., and Benner, S.A. (2004) Borate minerals stabilize ribose. Science 303:196.

Rondanelli, R. and Lindzen, R.S. (2010) Can thin cirrus clouds in the tropics provide a solution to the faint young Sun paradox? J Geophys Res 115:689-690.

Rosing, M.T, Bird, D.K., Sleep, N.H., and Bjerrum, C.J. (2010) No climate paradox under the faint Sun. Nature 464: 744-747.

Rowe, J.J., Fournier, R.O., and Morey, G.W. (1973) Chemical Analysis of Thermal Waters in Yellowstone National Park, Wyoming, 1960-1965, Geological Survey Bulletin 1303, US Government Printing Office, Washington, DC.

Rubin, A.E. (1997) Mineralogy of meteorite groups. Meteorit Planet Sci 32:231-247.

Ruiz-Mirazo, K., Briones, C., and de la Escosura, E. (2014) Prebiotic system chemistry: new perspectives for the origins of life. Chem Rev 114:285-366.

Russell, M.J. (2007) The alkaline solution to the emergence of life: energy, entropy and early evolution. Acta Biotheor 55: 133-179.

Russell, M.J. and Arndt, N.T. (2005) Geodynamic and metabolic cycles in the Hadean. Biogeosciences 2:97-111.

Russell, M.J. and Hall, A.J. (1997) The emergence of life from iron monosulphide bubbles at a submarine hydrothermal redox and pH front. J Geol Soc London 154:377-402.

Russell, M.J., Hall, A.J., and Martin, W. (2010) Serpentinization as a source of energy at the origin of life. Geobiology 8: 355-371.

Ryder, G., Koeberl C., and Mojzsis S.J. (2000) Heavy bombardment on the Earth at $\sim 3.85 \mathrm{Ga}$. The search for petrographic and geochemical evidence. In Origin of the Earth and Moon, edited by R.M. Canup and K. Righter, University of Arizona Press, Tuscon, AZ, pp 475-492.

Sagan, C. and Mullen, G. (1972) Earth and Mars: evolution of atmospheres and surface temperatures. Science 177:52-56. 
Saha, R., Pohorille, A., and Chen, I.A. (2014) Molecular crowding and early evolution. Orig Life Evol Biosph 44:319-324.

Sephton, M.A. (2002) Organic compounds in carbonaceous meteorites. Nat Prod Rep 19:292-311.

Shock, E.L., McCollom, T.M., and Schulte, M.D. (2002) The emergence of metabolism from within hydrothermal systems. In Thermophiles: The Keys to Molecular Evolution and the Origin of Life, edited by J. Wiegel and M.W.W. Adams, Taylor \& Francis, London, pp 59-76.

Simoncini, E., Russell, M.J., and Kleidon, A. (2011) Modelling free energy availability from Hadean hydrothermal systems to first metabolism. Orig Life Evol Biosph 41:529-532.

Sleep, N.H. (2000) Evolution of the mode of convection within terrestrial planets. J Geophys Res 105:17563-17578.

Sleep, N.H. (2016) Asteroid bombardment and the core of Theia as possible sources for the Earth's late veneer component. Geochem Geophys Geosyst 17, doi:10.1002/2016GC006305.

Sleep, N.H., Zahnle, K., and Neuhoff, P.S. (2008) Initiation of clement surface conditions on the earliest Earth. Proc Natl Acad Sci USA 98:3666-3672.

Sleep, N.H., Bird, D.K., and Pope, E.C. (2011) Serpentine and the dawn of life. Philos Trans R Soc Lond B Biol Sci 366: 2857-2869.

Smith, J.V., Arnold, F.P., Parsons, I., and Lee, M.P. (1999) Biochemical evolution III: polymerization on organophilic silica-rich surfaces, crystal-chemical modeling, formation of first cells, and geological clues. Proc Natl Acad Sci USA 96: 3479-3485.

Spitzer, J. and Poolman, B. (2009) The role of biomacromolecular crowding, ionic strength, and physicochemical gradients in the complexities of life's emergence. Microbiol Mol Biol Rev 73:371-388.

Stern, R.J. (2005) Evidence from ophiolites, blueschists, and ultra-high pressure metamorphic terranes that the modern episode of subduction tectonics began in Neoproterozoic time. Geology 33:557-560.

Stern, R.J. (2008) Modern-style plate tectonics began in Neoproterozoic time: an alternative interpretation of Earth's tectonic history. In When Did Plate Tectonics Begin? Geological Society of America Special Paper 440, edited by K. Condie and V. Pease, Geological Society of America, Boulder, CO, pp 265-280.

Sugitani, K., Mimura, K., Takeuchi, M., Yamaguchi, T., Suzuki, K., Senda, R., Asahara, Y., Wallis, S., and Van Kranendonk, M.J. (2015) A Paleoarchean coastal hydrothermal field inhabited by diverse microbial communities: the Strelley Pool Formation, Pilbara Craton, Western Australia. Geobiology 13:522-545.

Tartèse, R., Chaussidon, M., Gurenko, A., Delarue, F., and Robert, F. (2017) Warm Archean oceans reconstructed from oxygen isotope composition of early-life remnants. Geochemical Perspectives Letters 3:55-65.

Tice, M.M. and Lowe, D.R. (2004) Photosynthetic microbial mats in the 3,416-Myr-old ocean. Nature 431:549-552.

Tice, M.M. and Lowe, D.R. (2006) Hydrogen-based carbon fixation in the earliest known photosynthetic organisms. Geology 34:37-40.

Tivey, M.K. and Delaney, J.R. (1986) Growth of large sulfide structures on the Endeavour Segment of the Juan de Fuca Ridge. Earth Planet Sci Lett 77:303-317.

Trevors, J.T. (2010) Perspective: Researching the transition from non-living to the first microorganisms: methods and experiments are major challenges. J Microbiol Methods 81: 259-263.
Trevors, J.T. (2011a) Origin of microbial life: nano- and molecular events, thermodynamics/entropy, quantum mechanisms and genetic instructions. J Microbiol Methods 84:492495.

Trevors, J.T. (2011b) Hypothesized origin of microbial life in a prebiotic gel and the transition to a living biofilm and microbial mats. C R Biol 334:269-272.

Trevors, J.T. and Pollack, H. (2005) Hypothesis: the origin of life in a hydrogel environment. Prog Biophys Mol Biol 89:1-8.

van den Boorn, S.H.J.M., van Bergen, M.J., Nijman, W., and Vroon, P.Z. (2007) Dual role of seawater and hydrothermal fluids in Early Archean chert formation: evidence from silicon isotopes. Geology 35:939-942.

van den Boorn, S.H.J.M., van Bergen, M.J., Vroon, P.Z., de Vries, S.T., and Nijman, W. (2010) Silicon isotope and trace element constraints on the origin of $\sim 3.5 \mathrm{Ga}$ cherts: implications for Early Archaean marine environments. Geochim Cosmochim Acta 74:1077-1103.

Van Kranendonk, M.J. (2006) Volcanic degassing, hydrothermal circulation and the flourishing of early life on Earth: a review of the evidence from $c$. 3490-3240 Ma rocks of the Pilbara Supergroup, Pilbara Craton, Western Australia. Earth-Science Reviews 74:197-240.

Van Kranendonk, M.J. and Pirajno, F. (2004) Geological setting and geochemistry of metabasalts and alteration zones associated with hydrothermal chert and barite deposits in the $c a$. $3.45 \mathrm{Ga}$ Warrawoona Group, Pilbara Craton, Australia. Geochemistry: Exploration, Environment, Analysis 4:253-278.

Van Kranendonk, M.J., Smithies, R.H., Hickman, A.H., Wingate, M.T.D., and Bodorkos, S. (2010) Evidence for Mesoarchean (similar to $3.2 \mathrm{Ga}$ ) rifting of the Pilbara Craton: the missing link in an early Precambrian Wilson cycle. Precambrian Res 177:145-161.

Van Kranendonk, M.J., Kirkland, K.L., and Cliff, J. (2015) Oxygen isotopes in Pilbara Craton zircons support a global increase in crustal recycling at 3.2 Ga. Lithos 228-229:90-98.

von Damm, K.L. (1990) Seafloor hydrothermal activity: black smoker chemistry and chimneys. Annu Rev Earth Planet Sci 18:173-204.

von Damm, K.L., Lilley, M.D., Shanks, W.C., III, Brockington, M., Bray, A.M., O'Grady, K.M., Olson, E., Graham, A., Proskurowski, G., and the SouEPR Science Party. (2003) Extraordinary phase separation and segregation in vent fluids from the southern East Pacific Rise. Earth Planet Sci Lett 206:265-378.

Wächtershäuser, G. (1988) Before enzymes and templates: theory of surface metabolism. Microbiol Rev 52:452-484.

Walker, J.C.G. (1985) Carbon dioxide on the early Earth. Orig Life Evol Biosph 16:117-127.

Walter, M.R., Des Marais, D., Farmer, J.D., and Hinman, N.W. (1996) Lithofacies and biofacies of Mid-Paleozoic thermal spring deposits in the Drummond Basin, Queensland, Australia. Palaios 11:497-518.

Westall, F. (2016) Microbial palaeontology and the origin of life: a personal approach. Boll Soc Paleontol Ital 55:85-103.

Westall, F., de Ronde, C.E.J., Southam, G., Grassineau, N., Colas, M., Cockell, C., and Lammer, H. (2006a) Implications of a 3.472-3.333 Ga-old subaerial microbial mat from the Barberton Greenstone Belt, South Africa for the UV environmental conditions on the early Earth. Philos Trans $R$ Soc Lond B Biol Sci 361:1857-1875.

Westall, F., de Vries, S.T., Nijman, W., Rouchon, V., Orberger, B., Pearson, V., Watson, J., Verchovsky, A., Wright, I., Rouzaud, J.-N., Marchesini, D., and Anne, S. (2006b) The 
3.466 Ga Kitty's Gap chert, an Early Archean microbial ecosystem. In Processes on the Early Earth, Geological Society of America Special Paper 405, edited by W.U. Reimold and R.L. Gibson, Geological Society of America, Boulder, CO, pp 105-131.

Westall, F., Cavalazzi, B., Lemelle, L., Marrocchi, Y., Rouzaud, J.N., Simionovici, A., Salomé, M., Mostefaoui, S., Andreazza, C., Foucher, F., Toporski, J., Jauss, A., Thiel, V., Southam, G., MacLean, L., Wirick, S., Hofmann, A., Meibom, A., Robert, F., and Défarge, C. (2011) Implications of in situ calcification for photosynthesis in a $\sim 3.3$ Ga-old microbial biofilm from the Barberton greenstone belt, South Africa. Earth Planet Sci Lett 310:468-479.

Westall, F., Campbell, K.A., Bréhéret, J.G., Foucher, F., Gautret, P., Hubert, A., Sorieul, S., Grassineau, N., and Guido, D.M. (2015a) Archean (3.33 Ga) microbe-sediment systems were diverse and flourished in a hydrothermal context. Geology 43:615-618.

Westall, F., Foucher, F., Bost, N., Bertrand, M., Loizeau, D., Vago, J.L., Kminek, G., Gaboyer, F., Campbell, K.A., Bréhéret, J.-G., Gautret, P., and Cockell, C.S. (2015b) Biosignatures on Mars: what, where, and how? Implications for the search for martian life. Astrobiology 15:998-1029.

Wilde, S.A., Valley, J.W., Peck, W.H., and Graham, C.M. (2001) Evidence from detrital zircons for the existence of continental crust and oceans on the Earth 4.4 Gyr ago. Nature 409:175-178.

Zahnle, K., Arndt, N., Cockell, C., Halliday, A., Nisbet, E., Selsis, F., and Sleep, N.H. (2007) Emergence of a habitable planet. Planet Space Sci Rev 129:35-78.

Zellner, N.E.B. (2017) Cataclysm no more: new views on the timing and delivery of lunar impactors. Orig Life Evol Biosph 47:261-280.

Address correspondence to:

Frances Westall

CNRS-Centre de Biophysique Moléculaire

Rue Charles Sadron

45071 Orléans cedex 2

France

E-mail: frances.westall@cnrs-orleans.fr

Submitted 7 April 2017

Accepted 7 September 2017

\author{
Abbreviations Used \\ $\mathrm{JC}=$ Josefsdal Chert \\ $\mathrm{PIXE}=$ particle-induced X-ray emission
}

